\title{
Technical challenges in the construction of the steady-state stellarator Wendelstein 7-X
}

\author{
H.-S. Bosch ${ }^{1}$, R. C. Wolf ${ }^{1}$
}

J. Baldzuhn ${ }^{1}$, D. Birus ${ }^{1}$, T. Bluhm ${ }^{1}$, T.Bräuer ${ }^{1}$, H. Braune ${ }^{1}$, V.Bykov ${ }^{1}$, A. Cardella ${ }^{1}$, F. Durodié ${ }^{2}$, M. Endler ${ }^{1}$, V. Erckmann ${ }^{1}$, G. Gantenbein ${ }^{3}$, D. Hartmann ${ }^{1}$, D. Hathiramani ${ }^{1}$, P. Heimann $^{4}$, B. Heinemann ${ }^{4}$, C. Hennig ${ }^{1}$, M. Hirsch ${ }^{1}$, D. Holtum ${ }^{4}$, J. Jagielski ${ }^{5}$, J. Jelonnek ${ }^{3}$, W. Kasparek ${ }^{6}$, T. Klinger ${ }^{1}$, R. König ${ }^{1}$, P. Kornejew ${ }^{1}$, H. Kroiss ${ }^{4}$, J. G. Krom ${ }^{1}$, G. Kühner ${ }^{1}$, H. Laqua ${ }^{1}$, H. P. Laqua ${ }^{1}$, C. Lechte ${ }^{6}$, M. Lewerentz ${ }^{1}$, J. Maier ${ }^{4}$, P. McNeely ${ }^{1}$, A. Messiaen ${ }^{2}$, G. Michel ${ }^{1}$, J. Ongena ${ }^{2}$, A. Peacock ${ }^{4}$, T. S. Pedersen ${ }^{1,}$ R. Riedl ${ }^{4}$, H. Riemann ${ }^{1}$, P. Rong ${ }^{1}$, N. Rust $^{1}$, J. Schacht ${ }^{1}$, F. Schauer ${ }^{1}$, R. Schroeder ${ }^{1}$, B. Schweer ${ }^{2}$, A. Spring ${ }^{1}$, A. Stäbler ${ }^{4}$, M. Thumm ${ }^{3}$, Y. Turkin ${ }^{1}$, L. Wegener ${ }^{1}$, A. Werner ${ }^{1}$, D. Zhang ${ }^{1}$, M. Zilker ${ }^{4}$

T. Akijama ${ }^{7}$, R. Alzbutas $^{8}$, T. Andreeva ${ }^{1}$, E. Ascasibar ${ }^{9}$, M. Balden ${ }^{4}$, M. Banduch ${ }^{1}$, Ch. Baylard $^{* 1}$, W. Behr ${ }^{10}$, C. Beidler ${ }^{1}$, A.Benndorf ${ }^{1}$, T. Bergmann $^{1}$, C. Biedermann ${ }^{1}$, B. Bieg ${ }^{11}$, W. Biel ${ }^{10}$, M. Borchardt ${ }^{1}$, G. Borowitz ${ }^{1}$, V. Borsuk ${ }^{2}$ S. Bozhenkov ${ }^{1}$, R. Brakel ${ }^{1}$, H. Brand $^{12}$, T. Brown $^{13}$, B. Brucker ${ }^{4}$, R. Burhenn ${ }^{1}$, K.-P. Buscher ${ }^{1}$, Caldwell-Nichols ${ }^{1 *}$, A. Cappa ${ }^{9}$, A. Cardella $^{1 *}$, A. Carls ${ }^{1}$, P. Carvalho ${ }^{14}$, Ł. Ciupiński $^{15}$, M. Cole ${ }^{16}$, J. Collienne $^{10}$, A. Czarnecka ${ }^{15}$, G. Czymek ${ }^{10}$, G. Dammertz ${ }^{3}$, C.P. Dhard ${ }^{1}$, V.I. Davydenko ${ }^{17}$, A. Dinklage ${ }^{1}$, M. Drevlak ${ }^{1}$, S. Drotziger $^{3}$, A. Dudek ${ }^{1}$, P. Dumortier ${ }^{2}$, G. Dundulis ${ }^{8}$, P. v. Eeten ${ }^{1}$, K. Egorov ${ }^{1}$, T. Estrada ${ }^{9}$, H. Faugel $^{4}$, J. Fellinger ${ }^{1}$, Y. Feng ${ }^{1}$, H. Fernandes ${ }^{14}$, W.H. Fietz ${ }^{3}$, W. Figacz ${ }^{15}$, F. Fischer ${ }^{4}$, J. Fontdecaba $^{9}$, A. Freund ${ }^{10}$, T. Funaba ${ }^{7}$, H. Fünfgelder ${ }^{4}$, A. Galkowski ${ }^{15}$, D. Gates ${ }^{13}$, L. Giannone $^{4}$, J.M. García Regaña ${ }^{9}$, J. Geiger ${ }^{1}$, S. Geißler ${ }^{4}$, H. Greuner ${ }^{4}$, M. Grahl ${ }^{1}$, S. Groß ${ }^{1}$, A. Grosman $^{18}$, H. Grote ${ }^{1}$, O. Grulke ${ }^{1}$, M. Haas ${ }^{1}$, L. Haiduk ${ }^{19}$, H.-J. Hartfuß*1, J.H. Harris ${ }^{16}$, D. Haus $^{1}$, B. Hein ${ }^{1}$, P. Heitzenroeder ${ }^{13}$, P. Helander ${ }^{1}$, R. Heller ${ }^{3}$, C. Hidalgo ${ }^{9}$, D. Hildebrandt ${ }^{1}$, H. Höhnle ${ }^{6}$, A. Holtz ${ }^{1}$, E. Holzhauer ${ }^{6}$, R. Holzthüm ${ }^{4}$, A. Huber ${ }^{10}$, H. Hunger ${ }^{3}$, F. Hurd ${ }^{4}$, M. Ihrke $^{4}$, S. Illy ${ }^{3}$, A. Ivanov ${ }^{17}$, S. Jablonski ${ }^{15}$, N. Jaksic ${ }^{4}$, M. Jakubowski ${ }^{1}$, R. Jaspers ${ }^{20}$, H. Jensen $^{1}$, H. Jenzsch ${ }^{1}$, J. Kacmarczyk ${ }^{15}$, T. Kaliatk ${ }^{8}$, J. Kallmeyer ${ }^{1}$, U. Kamionka ${ }^{1}$, R. Karaleviciu $^{8}$, S. Kern ${ }^{3}$, M. Keunecke ${ }^{21}$, R. Kleiber ${ }^{1}$, J. Knauer ${ }^{1}$, R. Koch ${ }^{2}$, G. Kocsis ${ }^{22}$,A. Könies $^{1}$, M. Köppen ${ }^{1}$, R. Koslowski ${ }^{10}$, J. Koshurinovev ${ }^{23}$, A. Krämer-Flecken ${ }^{10}$, R. Krampitz ${ }^{1}$, Y. Kravtsov ${ }^{11}$, M. Krychowiak ${ }^{1}$, G. Krzesinski ${ }^{15}$, I. Ksiazek ${ }^{24}$, Fr. Kubkowska ${ }^{15}$, A. Kus ${ }^{1}$, S.

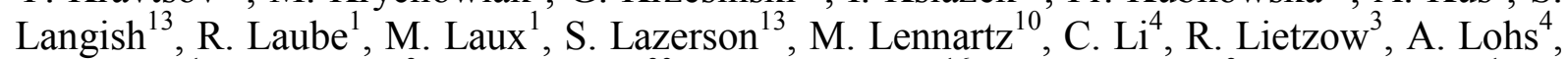
A. Lorenz ${ }^{1}$, F. Louche ${ }^{2}$, L. Lubyako ${ }^{23}$, A. Lumsdaine ${ }^{16}$, A. Lyssoivan ${ }^{2}$, H. Maaßberg ${ }^{1}$, P. Marek $^{15}$, C. Martens ${ }^{4}$, N. Marushchenko ${ }^{1}$, M. Mayer ${ }^{4}$, B. Mendelevitch ${ }^{4}, \mathrm{Ph}_{\text {. Mertens }}{ }^{10}, \mathrm{D}$. Mikkelsen $^{13}$, A. Mishchenko ${ }^{1}$, B. Missal ${ }^{1}$, T. Mizuuchi ${ }^{25}$, H. Modrow ${ }^{1}$, T. Mönnich ${ }^{1}$, T. Morizaki $^{7}$, S. Murakami ${ }^{25}$, F. Musielok ${ }^{24}$, M. Nagel ${ }^{1}$, D. Naujoks ${ }^{1}$, H. Neilson ${ }^{13}$, O. Neubauer $^{10}$, U. Neuner ${ }^{1}$, R. Nocentini ${ }^{4}$, J.-M. Noterdaeme ${ }^{4}$, C. Nührenberg ${ }^{1}$, S. Obermayer ${ }^{4}$, G. Offermanns ${ }^{10}$, H. Oosterbeek ${ }^{12}$, M. Otte ${ }^{1}$, A. Panin ${ }^{10}$, M. Pap ${ }^{10}$, S. Paquay ${ }^{12}$, E. Pasch ${ }^{1}$, X. Peng $^{1 *}$, S. Petrov ${ }^{26}$, D. Pilopp ${ }^{1}$, H. Pirsch ${ }^{4}$, B. Plaum ${ }^{6}$, F. Pompon ${ }^{4}$, M. Povilaitis ${ }^{8}$, J. Preinhaelter $^{27}$, O. Prinz ${ }^{3}$, F. Purps ${ }^{1}$, T. Rajna ${ }^{1}$, S. Récsei ${ }^{22}$, A. Reiman ${ }^{13}$, D. Reiter ${ }^{10}$, J. Remmel $^{10}$, S. Renard*1, V. Rhode ${ }^{4}$, J. Riemann ${ }^{1}$, S. Rimkevicius ${ }^{8}, K . R^{2} e^{1}$, A. Rodatos ${ }^{1}$, I. $\operatorname{Rodin}^{28}$, M. Romé ${ }^{29}$, H.-J. Roscher ${ }^{30}$, K. Rummel ${ }^{1}$, Th. Rummel ${ }^{1}$, A. Runov ${ }^{1}$, L. Ryc ${ }^{15}$, J. Sachtleben $^{1}$, A. Samartsev ${ }^{3}$, M. Sanchez ${ }^{9}$, F. Sano ${ }^{25}$, A. Scarabosio ${ }^{4}$, M. Schmid ${ }^{3}$, H. Schmitz $^{10}$, O. Schmitz ${ }^{10}$, M. Schneider ${ }^{1}$, W. Schneider ${ }^{1}$, L. Scheibl ${ }^{10}$, M. Scholz ${ }^{15}$, G. Schröder $^{10}$, M. Schröder ${ }^{1}$, J. Schruff ${ }^{10}$, H. Schumacher ${ }^{31}$, I.V. Shikhovtsev ${ }^{17}$, M. Shoji ${ }^{7}$, G. Siegl $^{4}$, J. Skodzik ${ }^{32}$, M. Smirnow ${ }^{4}$, E. Speth ${ }^{4 *}$, D.A. Spong ${ }^{16}$, R. Stadler $^{4}$, Z. Sulek ${ }^{19}$, V. Szabó $^{22}$, T. Szabolics ${ }^{22}$, T. Szetefi ${ }^{22}$, Z. Szökefalvi-Nagy ${ }^{22}$, A. Tereshchenko ${ }^{1}$, H. Thomsen ${ }^{1}$, M. Thumm ${ }^{3}$, D. Timmermann ${ }^{32}$, H. Tittes ${ }^{4}$, K. Toi ${ }^{7}$, M. Tournianski ${ }^{33}$, U. v. Toussaint ${ }^{4}$, J. Tretter $^{4}$, S. Tulipán ${ }^{22}$, P. Turba ${ }^{4}$, R. Uhlemann ${ }^{10}$, J. Urban $^{27}$, E. Urbonavicius ${ }^{8}$, P. Urlings ${ }^{12}$, S. Valet $^{1}$, D. Van Eester ${ }^{2}$, M. Van Schoor ${ }^{2}$, M. Vervier $^{2}$, H. Viebke ${ }^{1}$, R. Vilbrandt ${ }^{1}$, M. 


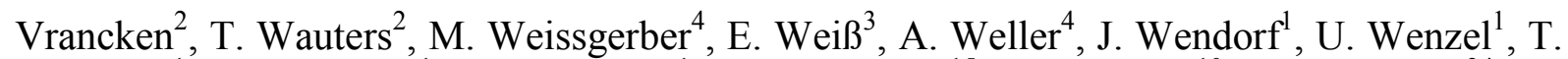
Windisch $^{1}$, E. Winkler ${ }^{1}$, M. Winkler ${ }^{1}$, J. Wolowski ${ }^{15}$, J. Wolters ${ }^{10}$ G. Wrochna ${ }^{34}$, P. Xanthopoulos $^{1}$, H. Yamada ${ }^{7}$, M. Yokoyama ${ }^{7}$, D. Zacharias ${ }^{1}$, J. Zajac ${ }^{27}$, G. Zangl ${ }^{4}$, M. Zarnstorff $^{13}$, H. Zeplien ${ }^{1}$, S. Zoletnik ${ }^{22}$, M. Zuin ${ }^{35}$

${ }^{1}$ Max-Planck-Institute for Plasma Physics, EURATOM Association, Wendelsteinstr. 1, 17491 Greifswald, Germany

${ }^{2}$ LPP/ERM-KMS, Association “EURATOM-Belgian State”, B-1000 Brussels, Belgium, TEC Partner

${ }^{3}$ Karlsruhe Institute of Technology, IHM, Association EURATOM-KIT, Karlsruhe, Germany

${ }^{4}$ Max-Planck-Institute for Plasma Physics, EURATOM Association, Boltzmannstr. 2, 85748 Garching, Germany

${ }^{5}$ The Andrzej Soltan Institute for Nuclear Studies, 05-400 Swierk/Otwock, Poland

${ }^{6}$ Institute for Plasma Research, University of Stuttgart, Stuttgart, Germany

${ }^{7}$ National Institute for Fusion Science (NIFS), 509-5292 Gifu, Toki, Japan

${ }^{8}$ Plasma Processing Laboratory, Lithuanian Energy Institute, Breslaujos 3, LT-3035 Kaunas,

Lithuania

${ }^{9}$ CIEMAT, Asociación EURATOM-CIEMAT para Fusión, Avenida Complutense 22, 28040 Madrid, Spain

${ }^{10}$ Forschungszentrum Jülich GmbH, Associaton EURATOM-FZ, D-52425 Jülich, Germany

${ }^{11}$ Institute of Physics, Maritime University of Szczecin (MUS), 1-2 Waly Chrobrego, Szczecin 70500, Poland

${ }^{12}$ Technische Universiteit Eindhoven, 5600 MB Eindhoven, The Netherlands

${ }^{13}$ Princeton Plasma Physics Laboratory (PPPL), PO Box 451, Princeton, NJ 08543, USA

${ }^{14}$ Associacao Euratom/IST, Instituto de Plasmas e Fusao Nuclear, Instituto Superior Técnico, Universidade Técnica de Lisboa, 1049-001 Lisboa, Portugal

${ }^{15}$ Warsaw University of Technology, EURATOM-IPPLM Association, Warsaw, Poland

${ }^{16}$ Oak Ridge National Laboratory, Oak Ridge, TN 37831, USA

${ }^{17}$ Budker Institute of Nuclear Physics, 630090 Novosibirsk, Russia

${ }^{18}$ Commissariat á L'Energie Atomique (CEA), Association EURATOM-CEA sur la fusion, CEA/ Cadarache 13108, St Paul Durance, France

${ }^{19}$ The Henryk Niewodniczanski Instiute of Nuclear Physics, IFJ PAN, 31-342 Krakow, Poland

${ }^{20}$ FOM-Institute for Plasma Physics Rijnhuizen, EURATOM Association, TEC, 3430 BE Nieuwegein, The Netherlands

${ }^{21}$ Fraunhofer Institut für Schicht- und Oberflächentechnik (IST), Bienroder Weg 54 E, 38108 Braunschweig, Germany

${ }^{22}$ Research Institute for Particle and Nuclear physics (KFKI-RMKI), EURATOM

Association, PO Box 49, H-1525 Budapest-114, Hungary

${ }^{23}$ Institute of Applied Physics (IAP), Russian Academy of Sciences, Ulyanova str. 46, 603950 Nizhny Novgorod, Russia

${ }^{24}$ Institute of Physics, University of Opole, Oleska 48, 45-052 Opole, Poland

${ }^{25}$ Institute of Advanced Energy, Kyoto University, Kyoto 606-8501, Japan

26 A.F. Ioffe Physical Technical Institute, 26 Polytekhnicheskaya, St Petersburg, 194021Russia

${ }^{27}$ IPP, Association EURATOM/IPP.CR, Za Solvankou 3, PO Box 17, 18221 Prague, Czech Republic

${ }^{28}$ Efremov Institute, St. Petersburg, Russia 
${ }^{29}$ Dipartimento di Fisica, Universit’a degli Studi di Milano (CNR),Via Celoria 16, 20133 Milano, Italy

${ }^{30}$ Fraunhofer Institut für Werkzeugmaschinen und Umformtechnik (IWU), Reichenhainer Straße 88, D-09126 Chemnitz, Germany

${ }^{31}$ Physikalisch-Technische Bundesanstalt (PTB), Bundesallee 100, D-38116 Braunschweig, Germany

${ }^{32}$ Institut für Physik, Universität Rostock, D-18051 Rostock, Germany

33 Culham Science Centre for Fusion Energy, EURATOM/CCFE Fusion Association, Abingdon, Oxfordshire OX14 3DB, UK

${ }^{34}$ The Andrzej Soltan Institute for Nuclear Studies, 05-400 Swierk/Otwock, Poland

${ }^{35}$ Consorzio RFX, Associazione EURATOM-ENEA sulla Fusione, 35127 Padova, Italy

Email-contact of main author: Bosch@ipp.mpg.de

\begin{abstract}
The next step in the Wendelstein stellarator line is the large superconducting device Wendelstein 7-X, presently under construction in Greifswald, Germany. Steady-state operation is an intrinsic feature of stellarators, and one key element of the Wendelstein 7-X mission is to demonstrate steady-state operation at plasma conditions relevant for a fusion power plant. Steady-state operation of a fusion device, on the one hand requires the implementation of special technologies, giving rise to technical challenges during the design, fabrication and assembly of such a device. On the other hand, also the physics development of steady state operation at high plasma performance poses a challenge and careful preparation. The electron cyclotron resonance heating system, diagnostics, experiment control and data acquisition are prepared for plasma operation lasting 30 minutes. This requires many new technological approaches for plasma heating and diagnostics as well as new concepts for experiment control and data acquisition.
\end{abstract}

\title{
1. Introduction
}

The Wendelstein 7-X (W7-X) stellarator, under construction in Greifswald, will be the first "fully-optimized" stellarator [1] which combines a quasi-isodynamic magnetic field at finite plasma- $\beta$, with good confinement of the thermal plasma, improved confinement of the fast 
ions and an equilibrium configuration which, by minimizing Pfirsch-Schlüter and bootstrap currents, shows little dependence on plasma- $\beta$. The latter is required to achieve an equilibrium-independent resonant island divertor configuration. On the basis of a low magnetic shear rotational transform profile and an $t=\imath / 2 \pi=1$ resonance at the plasma edge, large magnetic islands, intersected by target plates, form the divertor. Other edge configurations $(t=5 / 4$ or 5/6) are possible within the experimental flexibility of W7-X.

The mission of the project is to demonstrate the reactor potential of the optimized stellarator line $[2,3]$. For the development of a credible stellarator reactor concept, steady-state operation has to be demonstrated for fully integrated discharge scenarios at high heating power yielding densities and temperatures relevant for a fusion reactor and with a divertor providing suitable power and particle exhaust. Steady-state operation is of utmost importance in fusion research, for both tokamak and stellarator devices. The development of plasma regimes which combine stability at high $\beta$, high $n \cdot T \cdot \tau_{E}$ and full control over plasma and impurity densities by means of island divertor operation - all under steady-state conditions is the chief scientific goal of Wendelstein $7-X$.

A prerequisite for operating steady-state plasmas consistent with these physics requirements, however, is the realization of a device involving all the engineering aspects of a steady-state fusion device imposing special technical challenges [4]. After a short description of the basic device (section 2) some of the technical challenges encountered in the design, manufacturing, and assembly of Wendelstein 7-X will be discussed. (sections 3 and 4).

To demonstrate that reactor relevant plasma parameters can be achieved in steady-state, the W7-X experiment is designed for plasma pulses with 30 minutes duration at a heating power of $10 \mathrm{MW}$. For this purpose the main heating system is an electron-cyclotron resonance heating (ECRH) facility consisting of ten $140 \mathrm{GHz}$ gyrotrons with up to $1 \mathrm{MW}$ microwave power each. In addition, $10 \mathrm{~s}$ pulses of neutral beam injection (stepwise upgrading from 3.5 to $20 \mathrm{MW})$ and ion cyclotron heating $(2-4 \mathrm{MW})$ are foreseen to access beta and equilibrium limits and to study fast ion confinement as well as fast ion driven instabilities (section 4).

Characteristic time scales range from energy confinement time and fast-ion slowing down time, which are in the order $100 \mathrm{~ms}$, to the L/R time for reaching an equilibrated magnetic field configuration, which is in the order of 30 seconds. The thermal equilibration time of actively cooled plasma-facing components and the time constants for plasma-wall interaction processes cover time ranges from seconds to hours or more. The large variety of time scales is strongly affecting the design of plasma diagnostics, data acquisition and device control [5], which is discussed in sections 5 and 6.

After the completion of the assembly, the start of operation of W7-X is foreseen in 2015. An initial phase of short-pulse operation $\left(1^{\text {st }}\right.$ operational phase) will be followed by the completion of the actively cooled in-vessel components including the replacement of the inertially cooled test-divertor by actively cooled high heat-flux targets. Afterwards $\left(2^{\text {nd }}\right.$ and further operational phases) plasma operation can be extended to 30 minutes at $10 \mathrm{MW}$ of heating power.

\section{The Wendelstein 7-X device}

The major radius of the $\mathrm{W} 7-\mathrm{X}$ plasma is $5.5 \mathrm{~m}$, the effective (i.e. averaged) minor radius is $0.55 \mathrm{~m}$. A schematic view of the basic device with its main components [4] is shown in FIG. 1. The pentagon-shape of the torus is clearly visible. The device consists of five nominally identical modules. Each of these is made out of two flip-symmetric parts, so that in fact the device is composed of 10 almost identical half-modules. 


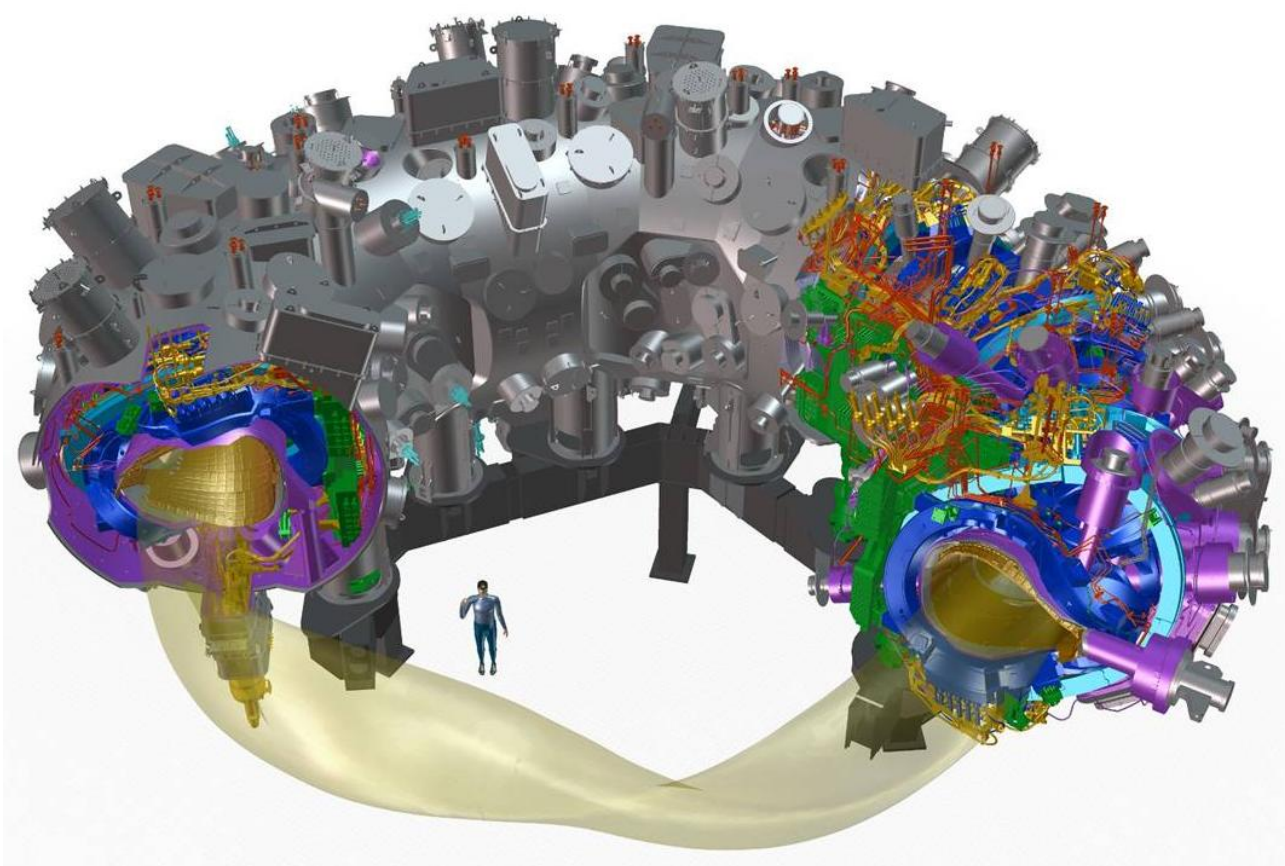

FIG. 1. Cutaway of a CAD drawing of W7-X showing the plasma (front), the modular (dark blue) and the planar (light blue) superconducting magnetic field coils attached to the central support ring (green) and the superconducting bus-bars (beige) and the cryo-piping (brown) together with part of the outer cryostat vessel (grey, upper left) and the ports (violet, right side).

The magnet system of $\mathrm{W} 7-\mathrm{X}$ is made from 50 non-planar coils for the basic magnetic field and 20 planar coils to allow for a variation of the magnetic field configuration (rotational transform and radial position of the plasma [6]), a bus-bar system to connect these coils electrically with each other and with the power supplies [7], a central support structure [8] and a set of support elements fixing the coils to the central ring and supporting them against each other [9]. According to the symmetry described before, each half-module is equipped with 5 non-planar coils of a different type and two slightly different planar coils.

The total mass of W7-X is 725 tons. The cold mass of the magnet system including central support ring amounts to 432 tons. The system is placed in a cryo-vacuum space created by the outer cryostat vessel [10], the plasma vessel [11] and 254 ports [12]. The ports allow access to the plasma vessel for heating, diagnostics, cooling of in-vessel components and pumping of the plasma vessel. On the cryo-vacuum side, a thermal shield is installed to minimize thermal radiation to the cold components. To provide the 70 superconducting coils $(7$ independent circuits) with a current of up to $18 \mathrm{kA}$, a set of 14 current leads, based on high temperature superconductors, will be used to connect the power supplies to the bus-bar inside the cryovacuum [13].

Most of the major components of Wendelstein 7-X have been manufactured, tested, delivered and assembled. Considerable progress of the device assembly over the last two years can be seen in FIG. 2, showing the status of September 2012. All five magnet modules have been equipped with bus-bars and cryo-piping, have been installed in the respective cryostat module and equipped with about 50 ports each and positioned finally on the machine base. As of now, 4 out of the 5 module separations have been closed, and the assembly of the in-vessel components $[14,15]$ and of peripheral components has started. 


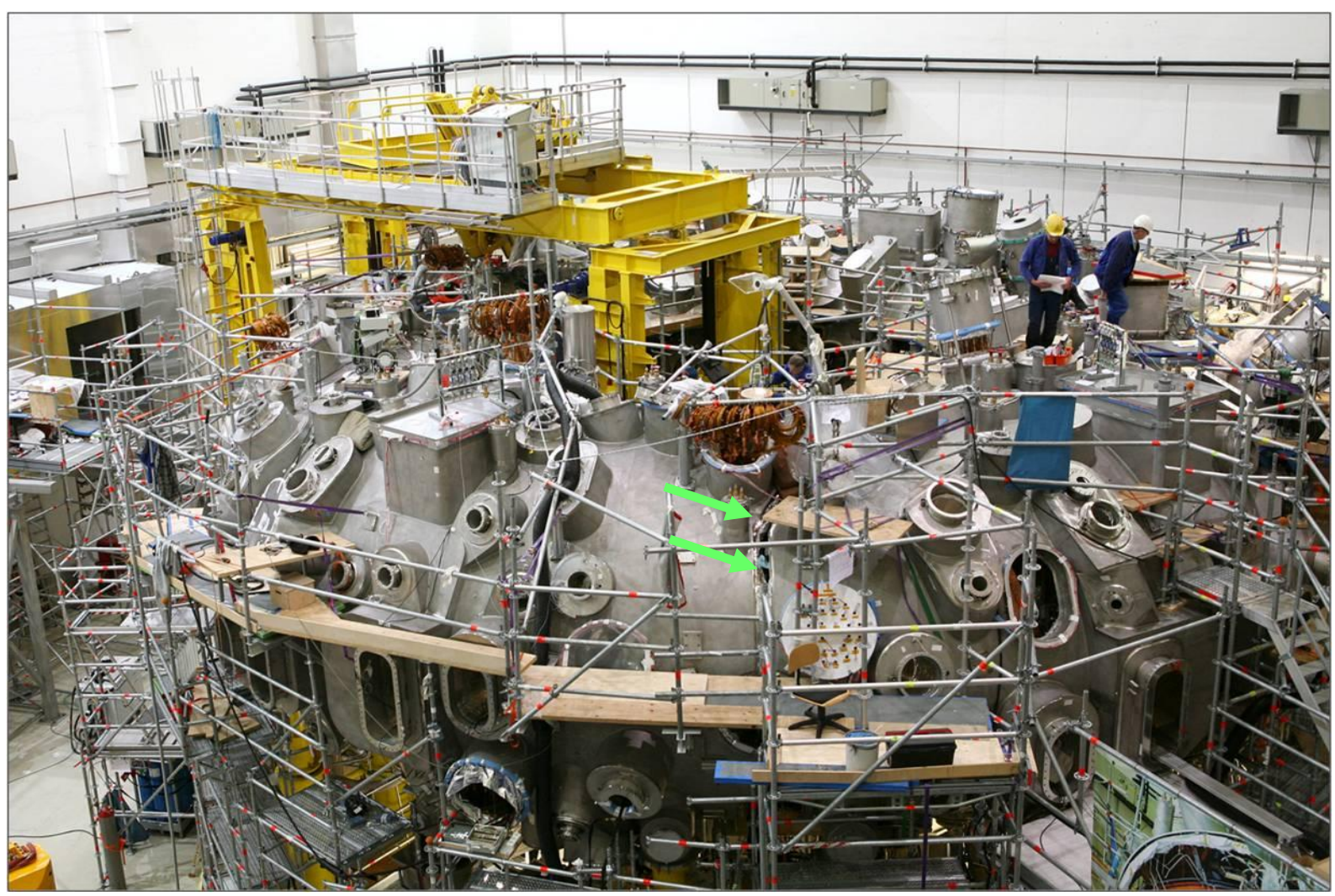

FIG. 2. View into the Wendelstein 7-X torus hall in September 2012. All five magnet modules in their respective cryostat module are in their final place. The green arrows indicate one of the two remaining module separations planes, the other three have been closed already. The yellow bridge like structure holds the so-called port ramp which here is used to install a port at one of the already closed module separation planes.

\section{Technical challenges}

While manufacturing a superconducting coil system with 70 coils of 7 different types already posed a challenge in itself [6], the largest challenge in the design, fabrication and assembly of Wendelstein 7-X was the required accuracy of the 3-dimensional magnetic field created by this coil system at the very end of this process.

Most of the magnetic configurations foreseen for the operation of $\mathrm{W} 7-\mathrm{X}$ will have a rotational transform $\mathrm{v} / 2 \pi=1$ at the boundary. At the plasma edge, i.e. outside the closed flux surfaces, the magnetic configuration of W7-X forms an intrinsic $n / m=5 / 5$ island structure which is used as an island divertor to control the power and particle exhaust from the confined plasma $[14,15]$. Such magnetic configurations are very sensitive to symmetry breaking perturbations resonant with $l / 2 \pi=1$ at the boundary and violating the toroidal periodicity of the magnetic field, e.g. $n / m=1 / 1$ or $n / m=2 / 2$. Due to the tolerances in the coil manufacturing process and magnet system assembly it is not possible to avoid all sources of these perturbations. Systematic deviations from the designed coil shapes and positions add only negligible field components and do not perturb the 5-fold symmetry of the machine, whilst the statistical deviations lead to a disturbance of the machine periodicity. The most critical consequences of such non-symmetrical deviations are modifications to the island topology. This leads to a small decrease in the volume of the confined plasma, and to a potentially significant redistribution of the power flux to the divertor modules, i.e. to an uneven power load distribution, and hence a potential overload of some of the divertor modules. These 
constraints create a challenge for the precision of the coil system construction itself, and also for its support structure.

\subsection{Accuracy of the superconducting coil system}

Magnetic field errors can be represented by a poloidal-toroidal Fourier decomposition of the radial component of the magnetic field perturbation on a flux surface at the plasma edge, $B_{m, n}$. In order to achieve an accurate magnetic field configuration and to guarantee the proper functioning of the island divertor, the resonant $(\mathrm{m}=\mathrm{n})$ components of the $B_{m, n}$, especially for the low mode numbers, have to be below $10^{-4} \cdot B_{00}[16]$.

Symmetry breaking perturbations can arise either from non-symmetric deviations in the coil shape during the coil manufacturing or from position displacements and coil deformations during the assembly process. In order to be able to achieve the high precision of coil manufacturing, a soft aluminium-conduit has been chosen for the superconductor, which allows for easier bending to the required accuracy [17]. Later, the finished winding pack was heat treated to harden the aluminium and to achieve the required strength of the conductor [6]. The coil winding process as well as the assembly of the coil has been monitored with an extensive metrology effort. For the 50 fabricated non-planar winding packs, the absolute average deviations of the central filament position from the CAD shape are $<3 \mathrm{~mm}$, and from the average shape for each coil type, the maximum deviation is in the order of $2 \mathrm{~mm} \mathrm{[16].} \mathrm{The}$ corresponding resonant magnetic field perturbation was kept at the level of

$$
\sqrt{{B_{11}}^{2}+B_{22}{ }^{2}+{B_{33}}^{2}+B_{44}^{2}} / 3 \mathrm{~T} \approx 0.8 \cdot 10^{-4},
$$

where $B_{00}=3 \mathrm{~T}$ is the maximum magnetic field of $\mathrm{W} 7-\mathrm{X}$.

During the assembly process, the position of each coil was monitored closely and precautions were taken to keep the position also during the welding of inter-coil supports (see below). According to specified assembly tolerances for coil and module positioning, all reference points measured had to be within a sphere with a radius of $1.5 \mathrm{~mm}$ with respect to their nominal value. Successive measurements of the reference points accompanied the main steps of the magnet system assembly and served as the basis for a continuous evaluation of the real magnetic configuration of $\mathrm{W} 7-\mathrm{X}$.

In order to compensate for the impact of the errors accumulated during coil system construction, it was decided to optimize the position of each of the five machine modules individually, based on the up-to-date set of geometric survey data of coil and module alignments. The principle of field error optimisation is that small perturbations have an almost linear behaviour, and the compensation is possible by a superposition of Fourier components with the same amplitude but with the opposite sign. One can compensate a limited number of low-order error-field Fourier components by appropriately shifting and rotating of the five magnet modules forming the W7-X magnet system.

This optimization must be performed within the space that is physically available - i.e. the module positioning must be consistent with the boundary conditions set by the surrounding structures. Therefore, the overall target function T consisted of a magnetic "quality function" $\mathrm{Q}$ (where a low value of Q represents a high "quality" of the magnetic field) and a function G which is responsible for the engineering restrictions: $T=Q+G$, where $G=g \sum_{j}\left(\exp \left(\frac{|\Delta j|^{2}}{0.9 l}\right)-1\right), \Delta j \equiv\left(\mathrm{r}_{\text {target, new }}-\mathrm{r}_{\text {target, old }}\right)[18]$.

Since the width of magnetic islands generated by the error field components scales as $\sim 1 / \mathrm{m}$, the weight of the amplitudes of the individual components should be chosen accordingly in a 
quality function to be minimized. The $(5,5)$ component does not break the toroidal periodicity and was therefore not considered. The high-order components were not considered since they have less importance. In addition, the relative amplitude of high-m components decreases faster with increasing distance from the coils than that of lower-m components. It was also decided to monitor a number of additional error field Fourier components during the optimisation process and to minimize their increase. Finally, the quality function for the magnetic field was chosen as $Q=Q_{0}+q_{1} Q_{1}, Q_{0}=\sum_{k=1}^{4} B_{k k}^{2} / k, Q_{1}=\frac{1}{2} B_{23}^{2}+\frac{1}{3} B_{34}^{2}+\frac{1}{4} B_{43}^{2}$. The weight factor $\mathrm{q}_{1}$ must be chosen such that the primary goal of the minimization of the edge-resonant part $\mathrm{Q}_{0}$ is granted while still achieving a certain reduction of $\mathrm{Q}_{1}$.

The input for these calculations were the real coil shapes after completion of their manufacture and the geometrical surveys of the coil positions after fixing the coils within their module and after placing of the module on the machine base. During the optimization procedure the module positions were varied by shifts and rotations, while the coil shapes and positions within the modules stayed unchanged, until a minimum of the target function $\mathrm{T}$ was found. The boundary conditions for any repositioning of the modules were that (i) the new target coordinates may not deviate by more than $5 \mathrm{~mm}$ from their values as measured at the moment when coils were aligned within a module and (ii) the true relative lateral shift of neighbouring modules may not exceed $10 \mathrm{~mm}$ at the central support structure, including measurement inaccuracies [18]. In addition, the shifts due to the change of target coordinates of all reference marks on the magnet system as well as the relative shifts of several positions on neighbouring modules were checked to insure the geometric boundary conditions. As an output, the optimized individual coordinates for the positioning of each of the five modules on the machine base were generated, which served as new target coordinates for all modules still to be positioned, leaving those untouched which were already located on the machine base. This calculation was performed before the positioning of each module on the machine base and followed by the evaluation of the updated magnetic field perturbations after the completion of the module adjustment based on the latest available survey data.

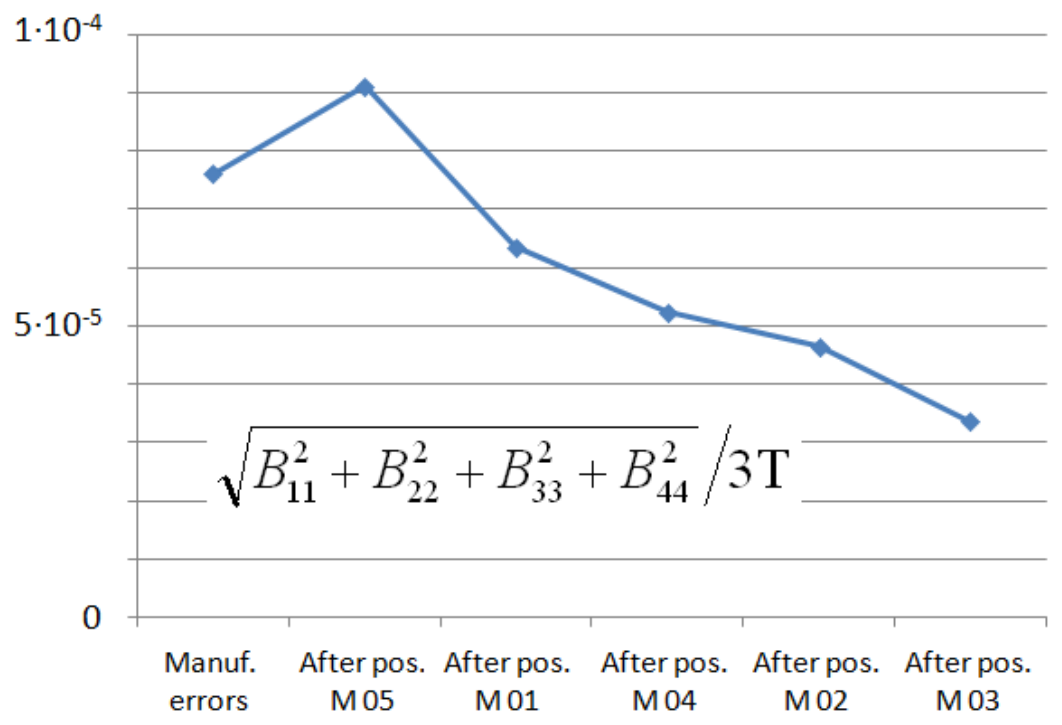

FIG. 3. Evaluation of the magnetic field perturbation during the assembly progress. The assembly sequence for the module positioning was M05-M01-M04-M02-M03.

The optimization results are illustrated in FIG. 3, representing the general evolution of the magnetic field perturbation during the assembly progress. The five modules were placed and 
positioned on the machine base sequentially. The assembly sequence for the module positioning was M05-M01-M04-M02-M03, where M0n reflects the internal numbering of the five machine modules. The magnetic field quality function $\mathrm{Q}$ was designed to minimise the field error for the standard magnetic configuration of $\mathrm{W} 7-\mathrm{X}$, characterized by equal currents in all non-planar coils and zero current in the planar coils.

This effort helped to avoid an error field accumulation during the assembly and served to even reduce the magnetic field perturbations by at least a factor $\sim 3$ in comparison with the initial level, which would have resulted from a module positioning according to the as-designed coordinates. The positioning of the magnet system was performed extremely accurately under the specified tolerances of $1.5 \mathrm{~mm}$ and worsens the theoretically attainable value insignificantly. For example, the relative magnetic field error after the positioning of the last module on the machine base is $0.34 \cdot 10^{-4}\left(\sqrt{\mathrm{B}_{11}^{2}+\mathrm{B}_{22}^{2}+\mathrm{B}_{33}^{2}+\mathrm{B}_{44}^{2}} / 3\right)$, as compared with $0.30 \cdot 10^{-4}$ for perfect positioning to the optimized target coordinates of the last module.

The value of the magnetic field perturbation was checked also for all other Wendelstein 7-X reference operating cases $[19,20]$ on the basis of the optimized coordinates, evaluated for the positioning of the last magnet system module. The error fields were also optimized for other reference configurations and are of the same order of magnitude as for the standard case.

\subsection{Structural stability of the superconducting coil system}

Wendelstein $7-\mathrm{X}$ is designed to operate with a magnetic field of $2.5 \mathrm{~T}$ on the plasma axis corresponding to the central absorption $2^{\text {nd }}$ harmonic electron cyclotron resonance heating at $140 \mathrm{GHz}$. The maximum magnetic field on the plasma axis is $3 \mathrm{~T}$. At these high magnetic field values the coil system of Wendelstein 7-X, consisting of 5 types of non-planar coils, will experience large forces: There are not only large centripetal forces (about $4 \mathrm{MN}$ per type 2 coil and more than $12 \mathrm{MN}$ per module) but also huge vertical forces (about $2.5 \mathrm{MN}$ per type 4 coil and more than $7 \mathrm{MN}$ per half-module). Also between the coils the forces are in the several-MN range (about $3 \mathrm{MN}$ per type 3 coil and more than $6 \mathrm{MN}$ per half-module). Therefore, at full current, the assurance of the mechanical integrity of the central support structure (CSS), coil casings and the inter-coil support system posed a big challenge. This was investigated in detail by finite-element (FE) calculations $[21,22]$ and a solution was found, consisting of a complex system of different support elements.

All the superconducting coils are attached to a robust $(10 \mathrm{~m}$ diameter and $2.5 \mathrm{~m}$ height $)$ central coil supporting structure. This is divided in five similar modules that are bolted together to form a pentagon-shaped ring, using large radial-vertical flanges in cast steel. Each of these five modules is in turn divided in two (flip-symmetric) half-modules, which are connected by bolts along a step-flange connection. Cooling pipes made of steel are thermally coupled to the CSS using copper stripes in order to keep the structure at cryogenic temperature $(3.9 \mathrm{~K})$. For their support all superconducting coils are provided with two extension blocks, which are welded to their casing. These blocks are bolted to the CSS using central support elements (CSE) consisting of massive supporting blocks welded to the CSS and a special system of high strength bolts. Huge forces (up to $4.4 \mathrm{MN}$ ) and bending moments (up to $450 \mathrm{kNm}$ ) have to be taken up by the CSEs. To keep the coils firmly but elastically in place, high strength, long and slender Inconel bolts and cylindrical extension sleeves have been used. These even allow opening of the flanges up to $70 \%$ for reduction of stresses [23]. As the coils have to be kept in their precise position also during cool down and operation, these central support fixtures have to be very rigid. The CSS is supported against the machine base with 10 special gravity supports (cryo-legs) including, as a thermal barrier, a part made of a glass-fibre reinforced plastic (GRP) tube, shrink-fitted into stainless steel rings with a thermal anchor in the middle [24, 25]. 
Large electro-magnetic forces between the non-planar coils are supported against each other with an inter-coil support system that can take up the forces and moments and keep their positions to a high accuracy. On the inner side of the torus, where the distance between coils is rather small (a few $\mathrm{cm}$ ) and accessibility is limited, so-called Narrow Support Elements are used. These are gliding elements that can take up contact forces up to $1.5 \mathrm{MN}$, sliding distances of up to $5 \mathrm{~mm}$, and tilting up to 1 degree during magnet energization [26]. On the outboard side of the torus, so-called Lateral Support Elements have been installed providing a rigid connection. These steel elements were welded between the neighbouring non-planar coils. The crucial issue here was the proper control of welding shrinkage, cracks and distortion which was essential to comply with the magnet system assembly tolerances. An extensive test program has been carried out to optimize the layout and welding procedures for these elements. In addition, all observed cracks were either repaired or assessed and accepted with respect to the number of operation cycles with a specified safety margin [27]. Between magnet modules, these elements are bolted to stainless steel "bridges" which were difficult to design and manufacture. These complex bridges are machined and installed with an accuracy better than $0.1 \mathrm{~mm}$ at every tilted side and $0.3 \mathrm{~mm}$ at the bottom. The machining was made according to surface scans of the corresponding coil areas and a photogrammetry of the gap between neighbouring coils. An aluminium dummy was produced first, then trial installation followed, and the fit was measured. With this geometry-correction the stainless steel "bridge" was finally fabricated and the coil transition part underwent a finite element (FE) structural analysis [28].

A special analysis strategy has been developed and implemented to study the highly nonlinear behaviour of the magnet system including fault scenarios [29, 30]. The approach includes intensive numerical studies with multiple parametric runs, taking into account the assembly tolerances achieved. Benchmarking between several independent FE global models was the key factor to eliminate all possible inaccuracies [31] and to define design values for each magnet system element. As a result, a tree of parametric FE models has been created and reused to support the assembly process of the machine and to assess proposed minor changes in the design and all reported non-conformities.

All critical support elements have been tested, using adequate mock-ups, and benchmarked with local FE models [26, 32, 33, 34]. A special conservative analysis procedure, taking into account the structural material degradation at $4 \mathrm{~K}$ in the form of serration effects, has been developed and implemented to accept local plastification in the support elements [35, 36, 37].

The possible influence of stick-slip events in the sliding supports and corresponding flanges on the coil conductor performance has been investigated in a specially designed test. A dynamic load was used to impact on one of the non-planar coils, at $4 \mathrm{~K}$ operating at its nominal current in its own magnetic field [38]. Thus, the mechanical effect of a stick-slip event was simulated. The required margin against mechanical disturbances of the superconducting wires inside the cable-in-conduit conductor was fully confirmed [39].

In order to monitor the structural behaviour of the complex magnet system during operation, to control the asymmetry and to benchmark the numerical representation, a special system of mechanical sensors has been developed and implemented [40, 41]. Several hundred signals will be permanently monitored during operation to assess the safe operation of the magnet system.

\subsection{Accuracy of the cryostat}

As mentioned in Section 2, the cryostat is composed of different components: The plasma vessel containing the plasma, the outer vessel, and the ports. The ports connect the two vessels and allow access from the outside into the plasma vessel, e.g. for diagnostics, heating, 
cooling media and pumping. These three components form the cryo-vacuum in which the cold mass is contained. The magnet system, fixed to the central support ring stands on 10 cryo-feet which are connected to the outer cryostat via bellows. Nevertheless, the plasma vessel has very small tolerances because the divertor target plates are attached to it and their position has to match the magnetic island geometry, determined by the magnetic field of the coils, very accurately. The functioning of the island divertor very sensitively depends on an even distribution of the heat loads from the plasma, which in turn relies not only on the aforementioned minimization of resonant field errors, but also on an accurate alignment of the divertor target plates. Also the outer vessel and the ports have very small geometrical tolerances of the order of a few millimetres as the space in the cryo-vacuum is very tightly packed.

With respect to the plasma and the outer vessel modules, which have been welded to the neighbouring modules, these small tolerances required an extended welding development to achieve minimal weld shrinkage. For the 254 ports, which have to be welded into the plasma vessel on one end and to the outer vessel on the other end, the situation was even more challenging. Positioning required rather small tolerances in order to avoid any collisions with components in the cryo-vacuum, e.g. coils and piping. Although there is a bellows in each port, also welding deformations had to be kept to a minimum in order not to overstress the port or to decrease the usable space when tilting both port tubes against each other. Therefore this assembly process required an extensive metrology effort and the development of specialized metrology [42] and welding procedures.

\subsection{Other challenges}

Other challenges, specific to Wendelstein 7-X, are the current leads and the space inside the cryo-vacuum. As the power supplies for the superconducting coils are located below the device, the current leads, which are the interface between these power supplies (at room temperature and ambient pressure) and the bus-bars inside the cryo-vacuum, have to be "upside-down", i.e. the cold end is on top, opposite of the usual configuration which makes use of the normal direction of the heat convection. However, this challenge has been met with current leads developed in cooperation with the Karlsruhe Institute for Technology [13, 43], which use a high temperature superconducting material, minimizing heat diffusion while maintaining excellent electrical conduction.

Cryo-piping and bus-bars [7] to provide the 70 superconducting coils with liquid helium for cooling and with electrical current have posed a specific challenge as the space within the cryostat is very tight. Both pipe and conductor systems are fixed on the central support ring and on the superconducting coils. These fixtures have to take up large forces and, at the same time, allow for movements, as the magnet system as well as the pipes/conductors move and deform during cool-down and energization of the coils. To allow for such movements, which have been calculated from the CAD-models with FE calculations [44, 45, 46], a demanding design process was necessary, including careful change management and configuration control $[47,48]$.

\subsection{Remaining assembly tasks}

As mentioned above (section 2), the Wendelstein 7-X torus is almost closed. However, there are still three major work packages ahead:

1) The assembly of about 2500 large in-vessel components, including 10 inertially cooled island divertor modules has just started. Most of these components are ready for assembly and 
the fabrication of the remaining components is running according to plan. The detailed assembly processes and logistics planning has been made over the past few years with emphasis on the assembly efficiency and assembly tolerances which again are very tight, i.e. in the order of $2-5 \mathrm{~mm}$.

(2) The assembly of the 14 current leads (see above) has commenced in late fall 2012. In the framework of a collaboration with the Oak-Ridge National Laboratory, the complicated assembly technology has been developed to install pairs of current leads together with the supporting structure and the corresponding part of the outer cryostat (the so-called dome). This procedure has meanwhile been tested using a 1:1 mock-up.

(3) The assembly of the device periphery (work platform, support structures, cable trays and cables, piping), heating units (10MW ECRH, two NBI boxes together equipped for 8 injectors), and diagnostics (about 20 systems) has started in parallel to the above listed work packages. As the simultaneous work on all these (partially inter-linked ) components requires a careful planning of the logistics and the work sequences, the torus hall layout and design principles have to be as consistent as possible. Therefore, about 60 sub-projects for these periphery components have been defined and detailed project specifications have been set up for each of these projects according to a common, well-defined structure. With these specifications, all the necessary information is available to implement the periphery components.

\section{Plasma heating}

The design of W7-X and in particular the layout of the ports include access for three different heating systems: Neutral beam injection (NBI), ion cyclotron resonance heating (ICRH) and electron cyclotron resonance heating $(\mathrm{ECRH})$. The port allocation with the injection geometries is shown in FIG. 4. At the beginning of the $1^{\text {st }}$ operational phase ECRH and NBI will be available. The expected minimum power levels at this stage are $7.5 \mathrm{MW}$ of ECRH (considering that not all gyrotrons achieve 1 MW) and 3.5 MW of NBI (hydrogen injection). The plan for ICRH foresees an installation of one antenna during the $1^{\text {st }}$ operational phase (OP1), delivering about $2 \mathrm{MW}$, and possible upgrades and further antennas for the $2^{\text {nd }}$ operational phase (OP2).

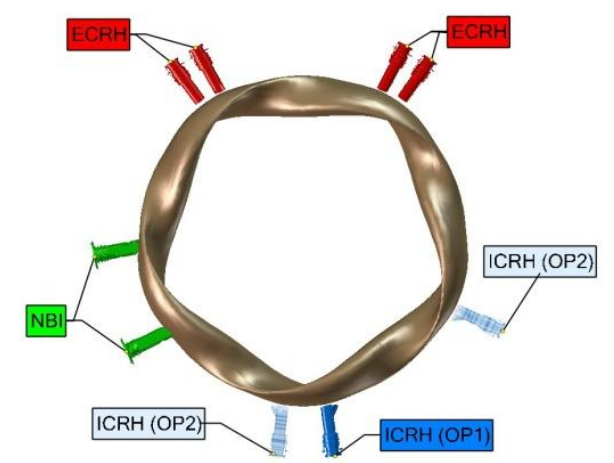

FIG. 4. Port allocation of the W7-X heating systems showing the positions and injection geometry of the plasma heating systems. ECRH and NBI will be available, at least partially, at the start of the $1^{\text {st }}$ operational phase (OP1). The present strategy foresees the installation of one ICRH antenna during $O P 1$ and up to two further antennas for or during the $2^{\text {nd }}$ operational phase (OP2). 


\subsection{Steady-state heating with ECRH}

Steady state plasma heating on W7-X will be provided by ECRH. The resonant coupling of microwaves to the gyro-motion of the electrons is a well established technique for electron heating and - by collisional transfer of their energy to the ions - also of the whole plasma. Since the gyro-frequency depends on the magnetic field, for a given frequency the wave coupling and hence the power deposition depends on the magnetic field. Owing to the spatial gradients of the magnetic field the power deposition usually exhibits a strong radial localization.

\subsubsection{ECRH facility}

The steady-state heating system for $\mathrm{W} 7-\mathrm{X}$ is an ECRH facility prepared for ten gyrotrons. Two spare installation positions exist for further upgrades. The design frequency of the gyrotrons is $140 \mathrm{GHz}$, corresponding to the $2^{\text {nd }}$ harmonic gyro-frequency of the electrons at $2.5 \mathrm{~T}$ [49]. Each gyrotron is designed for a steady-state output power of $1 \mathrm{MW}$. The specified acceptance criterion is a minimum of $900 \mathrm{~kW}$ in the linearly polarized fundamental Gaussian mode over 30 minutes. At present five gyrotrons have passed final acceptance tests and, hence, are ready for operation. At least three further gyrotrons will be manufactured before W7-X begins operation, yielding an initial total output power of about 7.5 MW. The gyrotrons can be operated also at $103 \mathrm{GHz}$ producing about half the output power and making ECRH possible also at $1.8 \mathrm{~T}$.

(a)

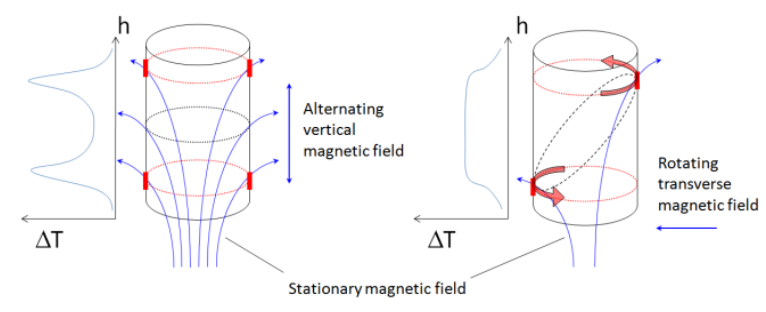

(b)

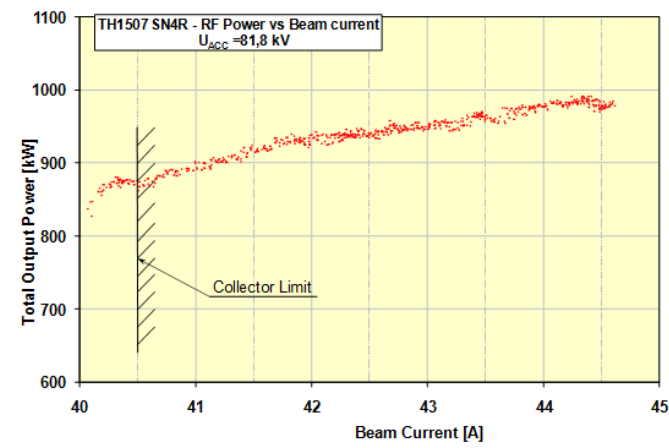

FIG. 5. (a) Illustration of the improved collector sweeping method. The figure on the left shows the old scheme with only an alternating vertical magnetic field. As a result, the electron beam is moved up and down and temperature peaks occur at the turning point. The figure on the right explains the effect of a transverse rotating magnetic field which removes these peaks and hence makes higher power levels possible. (b) Without the transverse rotating magnetic field the maximum allowable temperatures would have clamped the power below the specified $900 \mathrm{~kW}$ for the gyrotron shown. With the improved collector sweeping 1 MW has been achieved.

Although the gyrotron prototype development was successful, problems with meeting the performance requirements for the series gyrotrons led to several modifications which had to be implemented during series production [50]. This includes a new beam tunnel design to avoid spurious oscillations before the electron beam reaches the cavity and an improved power handling in the collector using a rotating transverse magnetic field [51]. Since the rotating transverse magnetic field reduces the peak loading in the turning points of the vertically swept electron beam inside the single-stage depressed collector, the overall power to the collector can be increased significantly. The principle of the rotating magnetic field is illustrated in FIG. 5(a). The effect on the output power of the gyrotron is illustrated in FIG. 
5(b). Owing to the improved collector sweeping the $1 \mathrm{MW}$ output power has been achieved despite efficiencies of approximately 40\%. In fact values slightly above $1 \mathrm{MW}$ could be sustained for $5 \frac{1}{2}$ minutes, limited by the temperature increase due to the absorption of microwave radiation by the shaft inside the gyrotron. Additional measures, which have been taken to improve the gyrotron performance, comprise a reduction of the microwave radiation absorption of the gyrotron shaft, an improved electrical insulation of the gyrotron body and a replacement of the water cooling of the gyrotron diamond window by oil cooling to prevent long term corrosion.

The microwave power from the gyrotrons is collected and relayed (through air) by a quasioptical system to the W7-X device [49]. Starting from the gyrotrons, individual optics produce a Gaussian beam shape. Subsequently the individual beams are combined and transmitted by a simple set of large mirrors towards W7-X, where they are separated again and fed into the launchers. For the coupling into the plasma four launchers are located at the low field side of two neighbouring magnet modules of W7-X where the magnetic field profile is tokamak like with approximately vertical iso-mod B contours. Each launcher is equipped with three front steering mirrors permitting for each gyrotron to individually change the poloidal and toroidal launch angles. At a given resonance-layer this means that for each gyrotron the vertical position of the deposition (in the poloidal plane) can be selected, and modifying the toroidal angle also the amount of current drive. All the transmission components are fabricated and tested. The quasi-optical transmission line has a very high efficiency, limiting the losses to about $7 \%$.

In addition to these main launchers which inject the microwave power from the low field side, the construction of two high field side (HFS) launchers has started, each designed to take up one gyrotron beam (i.e. up to $2 \mathrm{MW}$ in total). Because of the limited port size the remote steering concept is used which is the preferred solution for a power plant. While ECRH from the low field side mainly heats the bulk electrons, ECRH from the high field side couples preferably to fast electrons. Hence, a comparison of the confinement properties and the current drive efficiency of the two different electron energy distribution functions becomes possible, which is directly related to the optimized confinement properties of W7-X.

(a)

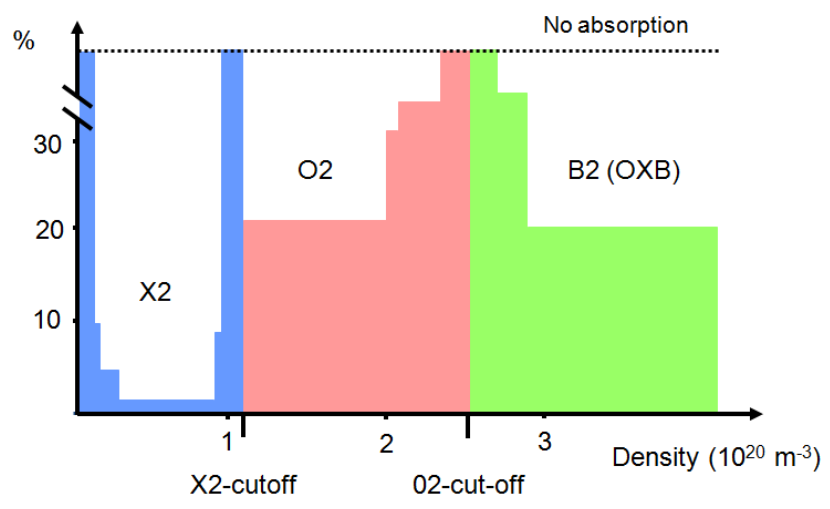

(b)

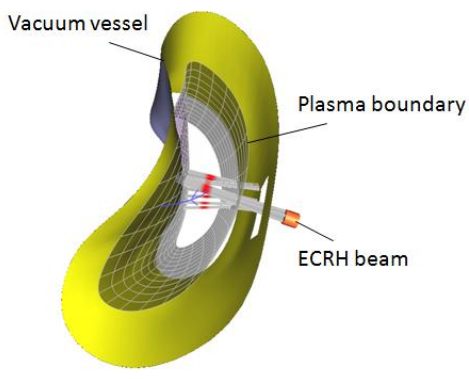

FIG. 6. (a) Principle sketch of the dependence of the percentage of non-absorbed power (for singlepass absorption) on the plasma density for the different heating schemes. In the standard density range up to $1 \times 10^{20} \mathrm{~m}^{-3}$ the $2^{\text {nd }}$ harmonic X-mode has a very high absorption. Beyond the cut-off the $2^{\text {nd }}$ harmonic O-mode can be used. This requires multi-pass absorption as illustrated in (b). Opposite to the ECRH launcher a high power mirror is installed. Further reflections of the micro-wave beam take place at the metallic surfaces of the in-vessel components between plasma vessel and plasma boundary. 


\subsubsection{Plasma heating scenarios}

In the absence of an inductive plasma current, the plasma start-up requires plasma generation by an external heating method. For plasma start-up and at low plasma densities $2^{\text {nd }}$ harmonic $\mathrm{X}$-mode (X2) heating will be applied. The dependence of the coupled power on the plasma density is shown in FIG. 6 . As soon as the plasma density rises the initially low absorption will increase rapidly. Above the cut-off density of about $1.2 \times 10^{20} \mathrm{~m}^{-3}$ the X2-mode can be changed to the $2^{\text {nd }}$ harmonic O-mode by modifying the polarization and launch angle of the microwave radiation. Especially during this transition, but also during O2-heating the nonabsorbed power increases, generally requiring multi-pass absorption. The level of nonabsorbed power strongly decreases with increasing electron temperature. Beyond the O2-cutoff in principle Bernstein wave heating (at the $2^{\text {nd }}$ harmonic) is possible providing wave absorption by the $\mathrm{O}-\mathrm{X}-\mathrm{B}$ conversion process.

\subsection{Ion cyclotron resonance heating}

The resonant heating of ions by electromagnetic waves in the radio frequency range (several tenths of $\mathrm{MHz}$ ) is a long established technique in magnetic confinement fusion experiments. Depending on magnetic field, chosen radio frequency and plasma composition, ICRH can be applied to heat the ions of the bulk plasma (majority absorption), a minority population of ions (minority absorption) producing a fast ion population which slows down on the plasma electrons or to directly heat the electrons which even offers the possibility of current drive if the waves are launched asymmetrically. The ICRH system will not be designed for steadystate heating. Aiming at about $10 \mathrm{~s}$ heating pulses such a system provides a heating and current drive tool complementing the steady-state ECRH for short periods. During periods when no ICRH is applied the antenna can be withdrawn into the port to avoid plasma aperture limitations to any of the magnetic configurations and to reduce the heat loads from the plasma and thus the steady-state cooling requirements.

(a)

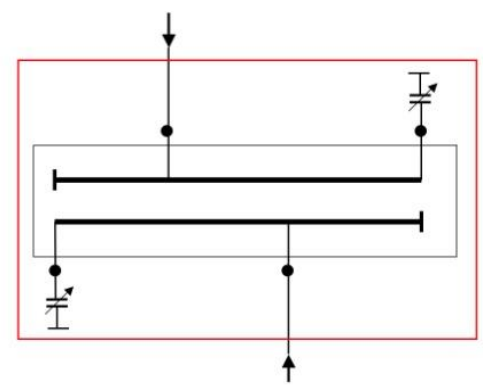

(b)

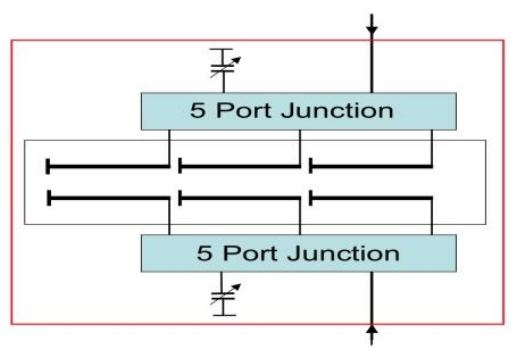

FIG. 7. Schematic outline of the 25-38 MHz (a) and $76 \mathrm{MHz}$ antenna (b) for W7-X.

For the dedicated ICRH system in W7-X two versions for antenna housings and strap assemblies are proposed. A first version covering the frequency band $25-38 \mathrm{MHz}$ and allowing $\mathrm{H}$ or ${ }^{3} \mathrm{He}$ minority heating at $\omega=\omega_{\mathrm{ci}}$ and a second version for operation near $76 \mathrm{MHz}$ for $\omega=2 \omega_{\mathrm{cH}}$ minority heating. For the first version the TEXTOR generators can be used. The second version can be implemented depending upon the availability of the necessary generator at $76 \mathrm{MHz}$. The geometry of these antennas in the available space of the dedicated port has been optimized for the best coupling conditions to a reference plasma density profile. The first antenna version consists of a pair of single straps, each of them being tuned by a vacuum capacitor at the rear of the antenna housing box and fed at a tap (FIG. 7a). The second version consists of a pair of strap triplets fed by a tunable 5-port junction $(F I G$. $7 b)$. The 5-port junction with its vacuum capacitor is also placed at the rear of the antenna box in the antenna port, similar to the 4-port junction proposed for the ICRF 
antenna for ITER [52]. The matching systems to the power source (or sources) allow $(0, \pi)$ toroidal phasing for fast particle generation / plasma heating, $(0,0)$ phasing for wall conditioning. Also $(0, \pm \pi / 2)$ phasing for current drive is possible if externally the two pairs are connected by a de-coupler to neutralize the mutual coupling between the 2 straps (or triplets) of each pair.

The antenna and vacuum feeding lines are supported by an external linear motion table and installed in a rectangular port close to the equatorial plane of W7-X (see FIG. 8). The table is designed to allow a radial movement of the antenna by $330 \mathrm{~mm}$ to optimize the RF power coupling to the plasma at different plasma configurations. For impedance matching of the 25-38 MHz version, an adjustable capacitor is connected to each of the 2 straps. The coaxial transmission lines serve also as main mechanical support for the antenna housing box, strap assembly and capacitors. The straps, antenna box and capacitors are water cooled. Various diagnostics for detection of temperatures, RF power, electrical field and plasma parameters are foreseen in the antenna box.

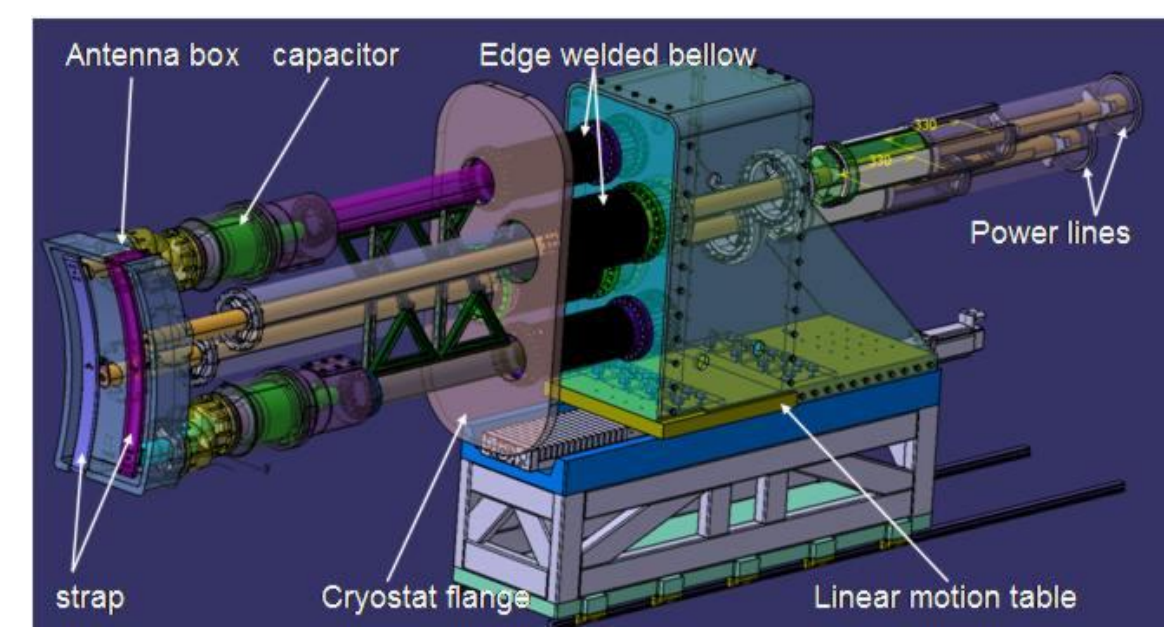

FIG. 8. ICRH antenna system for operation in a frequency range of 25-38 MHz at W7-X

\subsection{Neutral Beam Heating}

The neutral beam heating system [53] for W7-X is a positive ion based system similar to the one currently operational on the ASDEX Upgrade Tokamak (AUG). The number of ion sources and injector boxes to be initially installed is still under discussion (most likely configuration at start is one injector with 2 sources), but with all eight sources (in two injector boxes) installed injection of $19 \mathrm{MW}$ (Deuterium) into the stellarator will be possible. The injector boxes can deliver beams for up to 10 seconds and require a 5 minute pause between beam injections. The beam power can be used to explore plasma stability and the equilibrium properties of W7-X at high $\beta$.

The W7-X NBI will use state of the art, RF driven, large extraction area hydrogen ion sources identical to those developed for the second AUG injector. For the $1^{\text {st }}$ operational phase of W7-X the NBI sources will have an acceleration voltage of $55 \mathrm{kV}$ for hydrogen or $60 \mathrm{kV}$ for deuterium. At a later date the acceleration voltage can be increased to $100 \mathrm{kV}$ for deuterium ( $72 \mathrm{kV}$ for hydrogen) by re-gapping the grids of the sources.

FIG. 9 shows the dependence of the shine-through on the plasma density for deuterium injection at $60 \mathrm{kV}$ (a) and $100 \mathrm{kV}$ (b) respectively. As the shine-through is independent of whether co- or counter-injection is used these results are valid for both injector boxes. In the 
case of $100 \mathrm{kV}$ the power load to the inner wall is about a factor of 2 higher at medium densities $\left(\sim 0.8 \times 10^{20} \mathrm{~m}^{-3}\right)$ than for $60 \mathrm{kV}$. For higher densities $\left(>1.5 \times 10^{20} \mathrm{~m}^{-3}\right)$ the difference of the shine-through is negligible, as in both cases for these densities plasma absorption is strong. In this high density range the $100 \mathrm{kV}$ acceleration voltage has the advantage of a greater penetration depth. For $100 \mathrm{kV}$ the power deposition profile is still centrally peaked, while the power deposition profile for $60 \mathrm{kV}$ is becoming hollow; resulting in off-axis heating above $1.5 \times 10^{20} \mathrm{~m}^{-3}$.

(a)

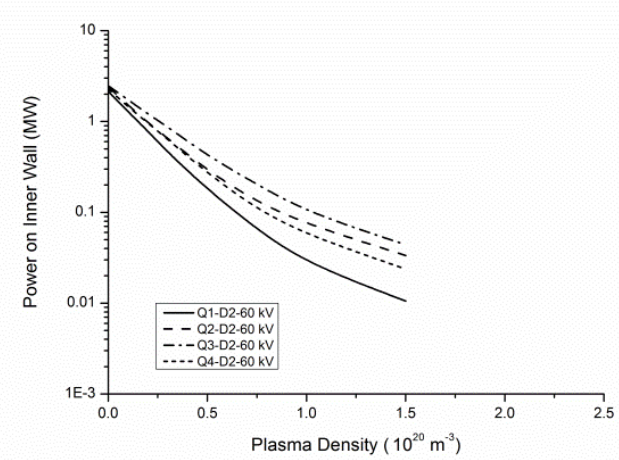

(b)

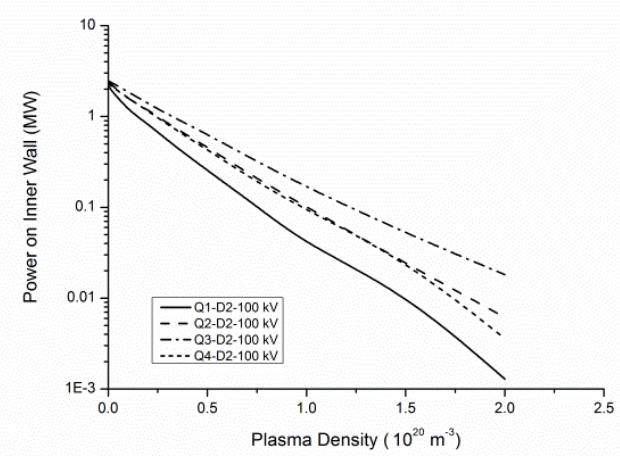

FIG. 9. Shine-through power on the W7-X inner wall for $2.5 \mathrm{MW}$ of injected power as a function of plasma density. The sources are operated in deuterium at an acceleration voltage of $60 \mathrm{kV}(\mathrm{a})$ and $100 \mathrm{kV}(b)$. Source $1(Q 1)$ and source $4(Q 4)$ are the sources that inject more tangential with the other two sources $2(Q 2)$ and $3(Q 3)$ the more radial.

In W7-X the field of the machine will always be present during the experimental day; this field makes it impossible to use titanium sublimation pumps heated by DC current as is presently done at AUG. For injector operation a pumping system capable of dealing with the gas from the four ion sources and neutralizers $(\sim 20000 \mathrm{~Pa}-1 / \mathrm{s})$ is required. At a test stand currently entering commissioning at IPP Garching it will be investigated if it is possible to develop a titanium sublimation pump heated by AC current that can operate reliably in the field of W7-X. The alternative is a conventional cryogenic pump system; but it still has to be determined if the pumps can be used in conjunction with the existing W7-X cryogenic plant or if a smaller satellite plant will be necessary.

A collaboration with the National Centre for Nuclear Research (NCBJ) in Poland was started in 2011. They will be responsible for the support structures of the injector boxes, torus gatevalves, bending magnets of the residual ion removal system, and the cooling water plant. All of these projects are well under way and delivery of all items is planned to be completed in 2013. Construction of the overall heating system is well advanced with the injector boxes entering the final assembly phase before being moved into the torus hall in the summer of 2013. The boxes should be connected to the machine in early 2014. Secondary services (cooling water, vacuum, gas, and RF generators) will be installed on site in 2013 and 2014. Commissioning of the ion sources will begin late 2014 or early 2015 and first injection should occur in summer of 2015.

During beam injection a fraction of the injected ions will be lost with appreciable energy and largely localized. To see what effect this would have on the machine a theoretical investigation via a computer simulation using the ANTS code [54] determined where these particles would impact the inner surfaces of the machine. The power loads are as high as $2 \mathrm{MW} / \mathrm{m}^{2}$, which is acceptable for the divertor elements but considerably above the 
$\sim 500 \mathrm{~kW} / \mathrm{m}^{2}$ that stainless steel wall elements can tolerate for 10 seconds. Additionally, a fraction of the ions enter the ducts at very shallow angles due to the ions following the magnetic field of W7-X. These impacts result, in some cases, in a heat load of $\sim 500 \mathrm{~kW} / \mathrm{m}^{2}$ at the weld area of the duct. Further theoretical work is ongoing to improve both the simulation results and to better determine the location of the strike points of the fast ions. Clearly changes to some of the inner components of the machine (thickening of tiles, or introducing new tiles to block ions from hitting sensitive components) will need to be done. In addtion, a comprehensive optical survey system (cameras both visible and IR) should be in place to monitor the machine for hot spots. Lastly, a careful and conservative commissioning of the neutral beam heating system for each magnetic configuration of W7-X needs to be performed.

\section{Plasma diagnostics}

\subsection{Diagnostics Overview}

Wendelstein 7-X will go into operation with a range of plasma diagnostics [55]. The plan foresees subsequent upgrades, extensions and further diagnostics during the scientific exploitation of $\mathrm{W} 7-\mathrm{X}$. The present priorities with respect to the implementation of the diagnostics are determined by the requirements of W7-X commissioning, first plasma operation and the initial experimental programme. The commissioning of $\mathrm{W} 7-\mathrm{X}$ includes a verification of the vacuum magnetic field by flux surface measurements. First plasma operation requires measurements of the neutron production (neutron counters), the plasma energy (diamagnetic loop) and net-current (Rogowski coils), the plasma density (single channel interferometer), in-vessel observation (video diagnostic) and an impurity monitor (VUV spectrometers). At the start of the experimental programme further diagnostics are required, bolometers for the measurement of the plasma radiation, a Thomson scattering system measuring the radial profiles of electron temperature and density, and a measurement of the effective charge by bremsstrahlung. According to the present design and construction activities these diagnostics will be augmented step by step by another 21 diagnostic systems covering plasma parameters from the plasma core to the edge and divertor, and including information about the plasma equilibrium and symmetry.

\subsection{Steady state challenges}

\subsubsection{Convective and radiative loads from the plasma}

Steady-state plasma operation adds a completely new level of complexity to the diagnostic requirements (for a comprehensive overview see [59]). These range from convective and radiative heat loads from the plasma [56], and ECRH stray radiation, to maintaining the properties of optical diagnostics and many other diagnostic specific issues [57]. While only a few diagnostics are exposed to convective loads, radiative loads are a more prominent issue for all those diagnostics which have parts located close to the plasma. Calculations show that heat loads of up to $80 \mathrm{~kW} / \mathrm{m}^{2}$ have to be expected near the plasma. These loads can be dissipated by water cooling, typically implemented as stainless steel structures. In addition, observation windows, mirrors and apertures have to be water cooled. The heat fluxes onto windows and mirrors can be significantly reduced by restricting the apertures as far as possible, even down to pinhole size. Diagnostics, which do not have to observe the plasma continuously, are being protected by cooled shutters. 


\subsubsection{Stray radiation protection}

Although multi-pass absorption is foreseen for those plasma heating scenarios which have lower absorption, it is assumed that a significant level of stray radiation will remain. Due to multiple reflections in the plasma chamber the stray radiation becomes nearly isotropic behaving like a gas of photons. The local level of stray radiation depends on the source strength, the plasma absorption which, depending on the heating scenario, is a function of electron density and temperature, and the absorption by in-vessel components. Generally, the expected stray radiation level decreases with increasing distance from the ECRH launchers $[58,59]$, and is expected to vary by a factor of ten in W7-X. All in-vessel components, including diagnostics, cabling, etc., are required to withstand up to $50 \mathrm{~kW} / \mathrm{m}^{2}$ of continuous microwave power flux, corresponding to an operational limit set at a total non-absorbed microwave power of $1 \mathrm{MW}$. Critical in-vessel components, e.g. diagnostics and cabling, are tested inside the microwave stray radiation launch (MISTRAL) facility which is a large vacuum chamber made of aluminium for a high reflection coefficient and connected to one of the gyrotrons [60].

The general protection against the $50 \mathrm{~kW} / \mathrm{m}^{2}$ stray radiation comprises a combination of several measures. First, materials with a high absorption coefficient for microwave radiation should be avoided if possible. Where impossible, e.g. for electrically insulating materials or ceramics, the components need to be shielded by metallic covers with a low absorption coefficient and thermally connected to cooled structures to dissipate the remaining heat. This, however, can be in conflict with the requirements for efficient pumping inside the vacuum or basic diagnostic requirements. Examples are fast magnetic flux probes which cannot afford thick metal shields or bolometers which need a direct view onto the radiating plasma. In the latter case the bolometer foils are contained in a practically closed detector housing with a pinhole, forming a pinhole camera, measuring the line-integrated plasma radiation with metal resistive bolometer foils. In order to reduce the impact on the measurements by the microwave stray radiation, the bolometer foils are covered by a metal mesh and the inside of the detector-housing is coated with a microwave absorbing mixture of aluminium oxide and titanium oxide [61]. The coating reduces the stray radiation level inside the housing and the metal mesh screens the detectors from the remaining radiation. Together the two measures reduce the stray radiation signal by a factor of 300. Finally, some optical windows are transparent to microwaves. To avoid stray radiation escaping from the plasma vessel through these windows, they will be coated with microwave absorbing coatings. While in the IR region a satisfactory solution has not yet been found, a thin $(1 \mu \mathrm{m})$ indium tin oxide coating forms a highly microwave absorbing layer which is transparent to visible light [57].

\subsubsection{Diagnostic specific issues}

During long plasma operation, contamination of optical elements, such as mirrors or windows, is expected to be a major problem. In W7-X the main effect will be the build-up of hydrogen rich soft hydrocarbon layers. This not only influences the calibration of a diagnostic, but can lead to a complete loss of transmission. Already a few 30 minutes plasmas correspond to one year of short pulse plasma operation. Specific solutions to the contamination problem include cleaning techniques for mirrors [62] and, where applicable, pinhole observation optics to reduce the carbon deposition. Moreover, applying a small hydrogen gas flow between the vacuum window or first optical element and the pinhole during plasma operation will be used to reduce the build-up of coatings [63].

Other issues concern the operational stability of diagnostics and their way of signal processing over long time scales. Examples are the interferometer for measuring the line integrated density and the integration of the voltage signal of magnetic probes to determine 
the change of the magnetic flux. For the application on W7-X a digital integrator has been developed which compensates the amplifier drifts and has an output stage which is not limited by the dynamic range [64]. For the measurement of the plasma density it has been decided to use a so-called dispersion interferometer which, on the one hand, is insensitive to vibrations and capable of following fast density changes and, on the other hand, provides a stable density measurement which is insensitive to slow temperature changes [65]. The interferometer uses a single $\mathrm{CO}_{2}$-laser $(10,6 \mu \mathrm{m})$ and a frequency doubler so that two phase coupled laser beams $\left(1^{\text {st }}\right.$ and $2^{\text {nd }}$ harmonic) travel through the plasma. After travelling through the plasma also the frequency of the $1^{\text {st }}$ harmonic beam is doubled. The advantage of using the superposition of two harmonics of the same laser is that the measured phase shift is directly proportional to the line integrated density. Phase shifts in the order of $2 \pi$ allow the reconstruction of the signal by simple interpolation, should the signal be lost during operation. In addition, the superposition of the two harmonics significantly reduces the sensitivity of the instrument to vibrations as no separate reference arm is needed and both signals stem from identical geometrical path lengths.

\section{Steady-state control and data acquisition}

\subsection{Experiment control}

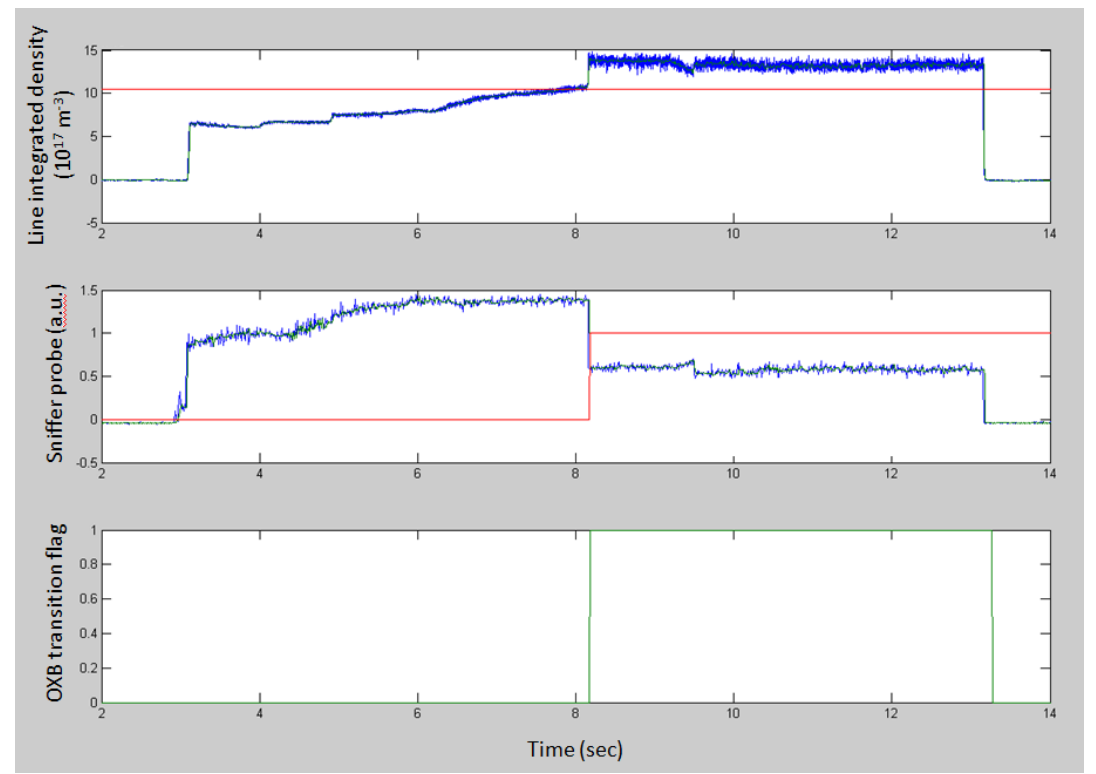

FIG. 10. Time traces of a WEGA plasma showing the line integrated plasma density, the signal of a sniffer probe which is a measure of the stray radiation level and the flag indicating the transition to another segment.

Long pulse or steady-state operation also requires new approaches to device and plasma control. For W7-X a segment based control frame work has been developed [66]. Experiment scenarios making use of the capabilities of W7-X and its subsystems (heating systems, diagnostics, etc.) will be handled by the control system. Thereby the flexibility of the control system allows running short pulses, steady-state plasmas and arbitrary sequences of phases with different characteristics in one plasma pulse. Technically this is implemented by scenarios which are subdivided into segments. In practise this means that a W7-X experiment 
programme can consist of a sequence of scenarios, each consisting of one or more segments. The segments describe the tasks for the various components (e.g. coil configuration, type of heating) involved in the experiment during that particular segment. The execution of the segments is performed dynamically depending on a variety of transition conditions which also can depend on plasma properties (adaptive control segment switch conditions) [67]. The editing of the experiment programme uses as far as possible high level parameters such as magnetic field on axis, magnetic shear, magnetic island position rather than asking for the programming of individual coil currents [68]. This control scheme has been extensively tested on the small stellarator WEGA [69]. An example of a plasma event driven segment transition is shown in FIG. 10. During the initial segment the plasma is heated by a magnetron and a gyrotron. The microwave radiation from the gyrotron is poorly absorbed, producing a high level of stray radiation (measured by the sniffer probe). As the power is ramped up, the plasma density rises. Eventually the plasma density exceeds the OXB conversion [70] threshold (red line in the density time trace). This is accompanied by the drop of the nonabsorbed microwave power. Subsequently the segment transition takes place and the plasma can be sustained by Bernstein wave heating with only the gyrotron applied [71].

\subsection{Data acquisition}

Long plasma pulse operation and the increasing number of measurement channels causes a significant increase of both data rates and the amount of data to be stored in the experiment data base. A prominent example is the monitoring of in vessel-components to protect them from overheating or elevated localized particle fluxes. Ten infrared cameras are foreseen to observe the actively cooled high heat flux divertor with a high spatial resolution. In addition, ten wide angle cameras will cover the entire in-vessel components in the visible range [57]. Altogether, data rates of the order of $30 \mathrm{Gbyte} / \mathrm{s}$ have to be handled. For a 30 minutes plasma experiment this means 50 Tbyte have to be collected and stored.

These huge amounts of data and the long plasma pulses demand special efforts for real time plasma control, and for continuous data acquisition and data archiving. The intended solutions comprise consequent data streaming and horizontally scalable network and storage systems. The data acquisition systems write the acquired data immediately onto network devices, one data stream for online data analyses and monitoring purposes and a second one for data archiving. The underlying network is based on 10 Gigabit/s technology and will be prepared for 40 and 100 Gigabit/s redundant uplinks to the core switching systems. The storage is a multi-tier system consisting of a highly available storage for e.g. radiation protection data (SAN with mirrored disks), highly scalable storage for most of the experiment data (IBM parallel file system GPFS) and a long term archive system (tape library with IBMs high performance storage system HPSS). The data acquisition software development is particularly demanding with respect to the reliability of the software for steady-state operation, since the likelihood of failing plasma experiments increases with plasma operation duration. For this reason much effort has been spent on the ability to perform tests and quality assurance in the software development process.

\section{Summary and outlook}

The remaining assembly steps described above are scheduled to be finished during the second half of 2014. The initial physics program of Wendelstein 7-X will start after the commissioning phase of about one year. In the first operational phase, the discharge duration will be limited to $6-10$ s at $8-15 \mathrm{MW}$ heating power. This limit is given by the inertially cooled island divertor installed for the first operation phase, which is robust against thermal 
overloads but allows for relatively short discharge pulses only [72]. It is the main purpose of the first operational phase to develop an integrated high-performance scenario which prepares the safe operation of the actively cooled island divertor with heating power in the $10 \mathrm{MW}$ range.

Regarding plasma heating, diagnostics, experiment control and data acquisition, most systems are designed and constructed for steady-state operation right from the start. The gyrotron development has shown that new technologies require continuous efforts to achieve the specified parameters and maintain the quality during production. For most of the diagnostics the steady-state capability has been included ab initio in the design requirements, as retrofitting would be very difficult. For the operation of a steady-state experiment a new control system has been devised and the data acquisition is designed to meet the real-time and steady state requirements.

\section{References}

[1] NÜHRENBERG, J., et al.; Overview on Wendelstein 7-X Theory, Trans. Fusion Technology 27, 71 (1995)

[2] BEIDLER, C. D., et al.; Fusion Technology 17, 148 (1990)

[3] WOLF, R. C., et al.; A stellarator reactor based on the optimization criteria of Wendelstein 7-X, Fusion Eng. Design 83, 990 (2008)

[4] BOSCH, H.-S., et al.; Construction of Wendelstein 7-X - Engineering a Steady-State Stellarator, IEEE Trans. Plasma Science 38, 265 (2010)

[5] GEIGER, J., WOLF, R. C., et al.; Aspects of Steady State Operation of the Wendelstein 7-X Stellarator, Plasma Phys. Control. Fusion 55 (2013) 014006

[6] RUMMEL, T., et al.; The superconducting magnet system of the stellarator Wendelstein 7-X, IEEE Trans. Plasma Science 40, 769 (2012)

[7] NEUBAUER, O., et al.; The busbar system for Wendelstein 7-X prepared for assembly and operational loads, Fusion Eng. Design 84 (2009) 1416

[8] CHAUVIN, D., KOPPE, T., CARDELlA, A., MISSAL, B., HEIN, B., PILOPP, D., Completion of design and manufacturing of the coil support structure of W7-X, Fusion Eng. Design 86, 640 (2011)

[9] CARDELLA, A., REICH, J., HEIN, B., KOPPE, T., MISSAL, B., PILOPP, D., WANNER, M., JENZSCH, H., KRAUSE, R., PLÖCKL, B., Construction of the Vacuum Vessels and the Magnet Supporting structure of Wendelstein 7-X, Fusion Eng. Design 82, 1913 (2007)

[10] KOPPE, T., CARDELlA, A., REICH, J., MISSAL, B., HEIN, B., KRAUSE, R., JENZSCH, H., Overview of main-mechanical-components and critical manufacturing aspects of the Wendelstein 7-X Cryostat, Fusion Eng. Design 86, 717 (2011)

[11] HEIN, B., CARDELlA, A., HERMANN, D., HANSEN, A., LEHER, F., BINNI, A., SEGL, J., Manufacturing and assembly of the plasma- and outer vessel of the cryostat for Wendelstein 7X. Fusion Eng. Design 87, 124 (2012)

[12] REICH, J., GARDEBRECHT, W., HEIN, B., MISSAL, B., TRETTER, J., WANNER, M., LEHER, F., LANGONE, S., Manufacture of the vacuum vessels and the ports of Wendelstein 7X, Fusion Eng. Design 75-79 565 (2005)

[13] HELLER, et al., High temperature superconductor current leads for fusion machines, Fusion Eng. and Design 86, 1422 (2011)

[14] RENNER, H., et al.; Physical Aspects and Design of the Wendelstein 7-X Divertor, Fusion Science Techn. 46, 318 (2004) 
[15] BOSCARY, J., et al.; Design and Technology Solutions for the Plasma Facing Components of Wendelstein 7-X., Fusion Eng. Design 86, 572 (2011)

[16] ANDREEVA, T., et al.; Influence of construction errors on Wendelstein 7-X magnetic configuration, Fusion Eng. Design 84, 408 (2009)

[17] RUMMEL, T., et al.; Accuracy of the construction of the superconducting coils for Wendelstein 7-X, IEEE Trans. Appl. Superconductivity 14, 1394 (2004)

[18] ANDREEVA, T., et al.; Evaluation of Wendelstein 7-X magnetic field perturbations during optimized module positioning, Proc. 39th EPS Conference, Stockholm, Sweden (2012)

[19] ANDREEVA, T., KISSLINGER, J., and WOBIG H., 2002, Characteristics of main configurations of Wendelstein 7-X, Problems of Atomic Science and Technology Series: Plasma Physics.", vol 4 pp. 45-47, Publisher: National Science Center, Kharkov Institute of Physics and Technology, http://vant.kipt.kharkov.ua/ARTICLE/VANT_2002_4/article_2002_4_45.pdf

[20] KISSLINGER, J., BEIDLER, C., HARMEYER, E., RAU, F. AND WOBIG, H., Magnetic field and coil systems of the modular HELIAS configuration HS 5-10, $16^{\text {th }}$ Symposium on Fusion Technology, 1990, Fusion Technology Vol. 2, pp 1520-1524, publisher Elsevier Science Publishers B.V., 1991, editor: KEEN, B.E. and HUGUET, M. and HEMSWORTH, R.

[21] BYKOV, V., et al.; Structural analysis of W7-X: Overview, Fusion Eng. Design 84, 215 (2009)

[22] BYKOV, V., et al,; Structural analysis of W7-X: from design to assembly and operation, Fusion Eng. Design 86, 645 (2011)

[23] CZARKOWSKI, P., et al.; Structural Analysis of the central support elements for the Wendelstein 7-X magnet system, Fusion Eng. Design 84, 636 (2009)

[24] EGOROV, K., BYKOV, V., SCHAUER, F., VAN EETEN, P., Structural analysis of Wendelstein 7-X magnet weight supports, Fusion Eng. Design 84, 722 (2009)

[25] JENZSCH, H., CARDELLA, A., REICH, J., GARDEBRECHT, W., BEDNAREK, M., SANCHES, P., SCHRADER, M., Final design and manufacturing of the Cryolegs of the W7-Xsuperconducting coil support system, Fusion Eng. Design, 83, 1600 (2008)

[26] HATHIRAMANI, D., et al.; Full scale friction test on tilted sliding bearings for Wendelstein 7X coils, Fusion Eng. Design 84, 809 (2009)

[27] FELLINGER, J., et al.; Assessment of cracks in lateral supports of the magnet system of Wendelstein 7-X, SOFT 2012, Oct. 2012 to be published in Fusion Eng. Design

[28] DUDEK, A., et al., Bolted coil support at the W7-X module interface, Fusion Eng. Design 86 $1402(2011)$

[29] BYKOV, V., et al., Strategy of Structural Analysis of W7-X Magnet System, Proc. 21 IEEE/NPS Symposium on Fusion Engineering 2005

[30] KÖPPEN, M., KIßLINGER, J., RUMMEL, T., MÖNNICH, T., SCHAUER, F., BYKOV, V., Simulations of W7-X magnet system fault scenarios involving short circuits, Fusion Eng. Des. 84, 1104 (2009)

[31] JAKSIK, N., VAN EETEN, P., BYKOV, V., SCHAUER, F., Analysis of the Magnet Support Structure for the Plasma Fusion Experiment Wendelstein 7-X, Computers and Structures 89, $1177(2011)$

[32] DUDEK, A., BYKOV, V., et al., Verification tests of critical bolted connections of the W7-X coils, Fusion Eng. Des. 84, 703 (2009)

[33] DAMIANI, C., BAUMEL, S., BENNDORF, A., BYKOV, V., et al., Design and test of the support elements of the W7-X magnet system, in: Proc.21 IEEE/NPS Symposium on Fusion Engineering 2005 
[34] VAN EETEN, P., HATHIRAMANI, D., BYKOV, V., et al, Design and test of the support elements of the W7-X superconducting magnets, Proc. 22 IEEE/NPS Symposium on Fusion Engineering 2007, paper P2_24

[35] FELLINGER, J., BYKOV, V., SCHAUER, F., Serrated yielding at cryogenic temperatures in structural components of Wendelstein 7-X, IEEE Transactions on applied superconductivity 22, 4801504 (2012)

[36] BRIANI, E., GIANINI, C., LUCCA, F., MARIN, A., FELlingER, J., BYKOV, V., Limit analysis of narrow support elements in W7-X considering the serration effect of the stress-strain relation at 4K, Fusion Eng. Design 86, 1462 (2011)

[37] CIUPINSKI, Ł., et al., Limit analysis of W7-X critical magnet system components with consideration of material serration effect, Fusion Eng. Design 86 (2011) 1501

[38] HATHIRAMANI, D., BERGMANN, T., BYKOV, V., et al., Stability Test of a Superconducting W7-X Coil With Respect to Mechanical Disturbances, IEEE Transactions on applied superconductivity 20, 543(2010)

[39] FELLINGER, J., FREUNDT, S., HATHIRAMANI, D., BYKOV, V., SCHAUER, F., Dynamic response analysis of superconducting coils in Wendelstein $7-\mathrm{X}$ and mechanical quench test, Fusion Eng. Design 861381388 (2011)

[40] KALLMEYER, P., CALDWELL-NICHOLS, Ch., CHEN, P., NITZ, M., SCHERWENKE, F., Instrumentation of W7-X cryo structure with advanced strain gauge sensors, 26th Symposium on Fusion Technology, P4-77, 2010

[41] CHEN, P., et al, Development of a Displacement Measurement System for Wendelstein 7-X Superconducting Magnet System, IEEE Transactions on Applied Superconductivity 21 (2011) 27

[42] BRÄUER, T., et al.; Metrology Support of Port Assembly at Wendelstein W7-X, Proc. 24th Symposium on Fusion Engineering, Chicago, 2011

[43] FIETZ, W., et al.; High temperature superconductor current leads for Wendelstein 7-X and JT60SA, IEEE Trans. Appl. Supercond. 19, 2202 (2009)

[44] DÜBNER, A., ZACHARIAS, D., NAGEL, M., BYKOV, V., SCHAUER, F., IHRKE, M., Structural analysis of the W7-X cryogenic pipe system, Fusion Eng. Design 84694 (2009).

[45] PANIN, A., et al, Sensitivity Study of Mechanical Behavior of Busbar System Designed for Wendelstein 7-X Stellarator, Fusion Engineering, 2007. SOFE 2007. 2007 IEEE 22nd, Digital Object Identifier : 10.1109/FUSION.2007.4337926, ISBN: 978-1-4244-1194-8

[46] GIESEN, B.; PANIN, A.; BOGUZEWSKI, T.; BRONS, S.; CHARL, A.; CZYMEK, G.; JOHN, A.; NEUBAUER, O.; SAUER, M.; SCHICK, R.; SZLAGOWSKA, J.; WOLTERS, J., Structural evaluation of the busbar system of Wendelstein 7-X stellarator, Fusion Engineering and Design 82 (2007) 1591-1598

[47] BRAKEL, R., et al.; Component design in tight areas in the cryostat of W7-X - configuration management and control, IEEE Trans. Plasma Science 38, 346 (2010).

[48] BAYLARD, C., et al.; Configuration Control Inside the W7-X Cryostat: Lessons Learned, Proc. 24th Symposium on Fusion Engineering, Chicago, 2011

[49] ERCKMANN, V., et al., "Electron Cyclotron Heating for W7-X: Physics and Technology", Fusion Science and Technology 52 (2007) 291

[50] GANTENBEIN, G., et al., $140 \mathrm{GHz}, 1 \mathrm{MW} \mathrm{CW}$ Gyrotron Development for Fusion Applications - Progress and Recent Results, J Infrared Milli TeraHz Waves, Vol 32, No 3 (2010) 320-28, ISSN 1866-6892, DOI 10.1007/s10762-010-9749-2 
[51] BRAUNE, H., et al. 2009, Advanced transverse field collector sweeping for high power gyrotrons, Strong Microwaves: Sources and Application, 2009, (Proc. VII Intern. Workshop, Nizhny Novgorod, Russia, 2008), Ed. A.G. Litvak, Vol. 1, p. 149-153

[52] DURODIÉ, F,. et al., "RF Optimization of the Port Plug Layout and Performance Assessment of the ITER ICRF Antenna", Proc. 24 ${ }^{\text {th }}$ IAEA Fusion Conf, San Diego, Paper ITR/P1-08

[53] MCNEELY, P., et al., submitted to Fusion Eng. Design (2013)

[54] DREVLAK, M., $36^{\text {th }}$ EPS Conference on Plasma Physics Sofia, Bulgaria, 2009, P4.211, published online and on $\mathrm{CD}$

[55] KÖNIG, R., et al., "Diagnostics design for steady-state operation of the Wendelstein 7-X stellarator", Rev. Sci. Instrum. 81 (2010) 10E133

[56] EICH, T., WERNER, A., Numerical Studies on Radiative Heat Loads to Plasma-Facing Components for the W7-X Stellarator, Fusion Science and Technology 53 (2008) 761-779

[57] KÖNIG, R., et al., "Diagnostic development for quasi-steady-state operation of the Wendelstein 7-X stellarator", Rev. Sci. Instrum. 83 (2012) 10D730

[58] LAQUA, H. P., et al. 2011 Distribution of the ECRH stray radiation in fusion devices In Proceedings of the 28th EPS Conf. Control. Fusion and Plasma Phys.,Funchal (Eds.) C. Silva, C. Varandas, D. Campbell, ECA 25A, European Physical Society, Geneva 2001, 1277-1280. http://www.cfn.ist.utl.pt/EPS2001/fin/pdf/P3.099.pdf

[59] HARTFUSS, H.-J., KÖNIG, R., WERNER, A., "Diagnostics for steady state plasmas", Plasma Phys. Control. Fusion 48 (2006) R83

[60] HATHIRAMANI, D., et al., "Microwave Stray Radiation, Measures for Steady State Diagnostics at Wendelstein 7-X", 27th Symposium on Fusion Technology (2012) http://sciconf.org/soft2012/ip/topic/d/session/p1/paper/37

[61] ZHANG, D., et al., "Design criteria of the bolometer diagnostic for steady-state operation of the W7-X stellarator", Rev. Sci. Instrum. 81 (2010) 10E134

[62] MARUYAMA, K., et al., J. Nucl. Mater. 264 (1999) 56

[63] MUKHIN, E. E., et al., Nucl. Fusion 52 (2012) 013017

[64] WERNER, A., "W7-X magnetic diagnostics: Performance of the digital integrator", Rev. Sci. Instrum. 77 (2006) 10E307

[65] DREIER, H., et al,. "First results from the modular multi-channel dispersion interferometer at the TEXTOR tokamak", Rev. Sci. Instrum 82 (2011) 063509

[66] LAQUA, H., et al., "Real-time software for the fusion experiment Wendelstein 7-X", Fusion Eng. Design 81 (2006) 1807

[67] LAQUA, H., et al. "Resource checking and event handling within the W7-X segment control framework", Fusion Eng. Design (2012)

http://www.sciencedirect.com/science/article/pii/S0920379612002839

[68] SPRING, A., et al., "A W7-X experiment program editor - A usage driven development", Fusion Eng. Design 84 (2012) 1954

[69] SCHACHT, J., et al., "Stellarator WEGA as a test-bed for the WENDELSTEIN 7-X control system concepts", Fusion Eng. Design 83 (2008) 228

[70] PODOBA, Y. Y., et al., "Direct Observation of Electron-BernsteinWave Heating by O-X-BMode Conversion at Low Magnetic Field in the WEGA Stellarator", Phys. Rev. Lett. 98 (2007) 255003

[71] OTTE, M., et al., "Overdense Plasma Operation in the WEGA Stellarator", Contrib. Plasma Phys. 50 (2010) 785/ DOI 10.1002/ctpp.200900053 
[72] BOSCH, H.-S., et al.; Physics Programme for Initial Operation of Wendelstein 7-X, Contrib. Plasma Phys. 50, 687 (2010) 